\title{
Conflictividad y órdenes mundiales Análisis y reflexión sobre las cuatro Cumbres ordenadoras del sistema internacional
}

\begin{abstract}
Wilson Fernández Luzuriaga* Hernán Olmedo González ${ }^{* *}$

\section{Resumen}

Este artículo se inserta en el marco de un proyecto de investigación que culmina el estudio de posibles relaciones entre estructura de poder, conflictividad y construcción de órdenes internacionales, a partir de cumbres multilaterales de gran relevancia: la Paz de Westfalia de 1648, el Congreso de Viena de 1815, la Conferencia de Paz de París de 1919 y la Conferencia de San Francisco de 1945. En una primera instancia, reitera una sistematización de datos cuantitativos sobre estructura del sistema internacional y sus niveles de conflictividad, este indicador derivado de tres datos específicos: número de grandes potencias en conflicto, duración, y severidad de los conflictos entre potencias. Sobre estos aspectos sistémicos del período 15002000, el trabajo presenta los siguientes resultados: en ningún momento el sistema registró una estructura unipolar, lo que predominó fue una estructura multipolar elevada; las guerras entre potencias antes de las cumbres de referencia fueron las más conflictivas; los períodos previos a las cumbres, el sistema registró sus mayores niveles de conflictividad. En una segunda instancia, analiza en forma comparada las consecuencias de las cumbres, teniendo en cuenta la ecuación normativa establecida en Westfalia: igualdad jurídica-soberanía-equilibrio de poder.
\end{abstract}

Palabras clave: conflictividad - equilibrio de poder - igualdad jurídica - soberanía

\section{Conflictivity and world orders Analysis and reflection on the four summits which ordered the international system}

\begin{abstract}
This article is inserted within a research project that approaches the study of possible relationships between power structures, conflict and the construction of international orders, focusing on four multilateral summits of great relevance: the Peace of Westphalia of 1648, the Congress of Vienna of 1815, the Paris Peace Conference of 1919 and the San Francisco Conference of 1945. Firstly, it reiterates a systematization of quantitative data about the structure of the international system and its level of conflict, this indicator being derived from three specific sources of variation: number of major powers in conflict, duration, and severity of conflicts between powers. Considering these systemic aspects during the 1500-2000 timeframe, the paper reveals the following findings: there were no instances of a unipolar structure, and what prevailed was a high multipolar structure; the wars between great powers previous to the summits were the most conflictive; during the periods previous to the summits the systems registered the highest levels of conflict. Secondly, it approaches in a comparative way the summits' consequences, taking into account the normative equation established in Westphalia: legal equality-sovereignty-balance of power.
\end{abstract}

Keywords: conflict - balance of power - legal equality - sovereignty

TRABAJO RECIBIDO: 09/03/2020 TRABAJO ACEPTADO: 24/04/2020

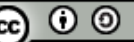

Esta obra está bajo una licencia internacional https://creativecommons.org/licenses/by-sa/4.0/

\footnotetext{
* Doctor en Ciencia Política. Profesor Adjunto, Programa de Estudios Internacionales de la Facultad de Ciencias Sociales, Universidad de la República (Udelar, Uruguay). Correo electrónico: wilson.fernandez@cienciassociales.edu.uy

** Doctor (c) en Ciencia Política. Coordinador Académico del Diploma de Posgrado en Estudios Internacionales, Programa de Estudios Internacionales de la Facultad de Ciencias Sociales, Universidad de la República (Udelar, Uruguay). Correo electrónico: hernan.olmedo@ cienciassociales.edu.uy
} 


\section{Introducción}

Este artículo constituye el último trabajo de un proyecto de investigación de gran alcance, cuyo objetivo medular residió en estudiar la relación entre estructura de poder, conflictividad y construcción de órdenes internacionales (Fernández Luzuriaga y Olmedo González, 2018, 2019a, 2019b, 2020). En efecto, se trata de un estudio orientado al logro de dos objetivos específicos: por un lado, explorar y comparar los niveles de conflictividad del sistema según el tipo de estructura o número de grandes potencias; por otro, comparar de qué manera la construcción de los cuatro órdenes internacionales -la Paz de Westfalia de 1648, el Congreso de Viena de 1815, la Conferencia de Paz de París de 1919 y la Conferencia de San Francisco de 1945-fueron construcciones funcionales a los intereses de las potencias predominantes del sistema. La relevancia de la investigación, justamente, consiste en reflejar que los acuerdos multilaterales intentaron dar respuesta a los cuatro períodos de mayor conflictividad del sistema internacional en los últimos quinientos años. En aras de generar una contribución en el campo de estudios de las Relaciones Internacionales mediante investigaciones sustentadas en el pluralismo epistemológico (Jackson, 2011), todo el proyecto de investigación, y este trabajo final en particular, se sustentan en la combinación de aproximaciones cuantitativas y cualitativas.

Partiendo de un problema central e inherente a las teorías sistémicas y estado-céntricas de las Relaciones Internacionales como lo es la relación entre estructura del sistema y conflictividad, la primera parte del trabajo presenta datos cuantitativos de las tendencias de la estructura del sistema internacional, sus niveles de conflictividad y los niveles de conflictividad de todas las guerras entre potencias libradas en los quinientos años transcurridos entre 1500-2000. El objetivo central de la primera parte es indagar si los períodos previos a la celebración de las grandes cumbres, fueron precedidos de niveles de alta conflictividad en el sistema, condicionados por guerras de alto nivel de conflictividad. La segunda parte se redacta con el objetivo de interpretar las respuestas normativas de la comunidad internacional a los contextos dados, mediante una estrategia narrativa que atienda el estudio de la evolución de las instituciones jurídicas. Dicha evolución es estudiada, particular, pero no exclusivamente, desde el pensamiento de la llamada Escuela de Montevideo de Derecho Internacional Público, que nuclea trabajos de las cátedras de Derecho Internacional Público en Uruguay desde 1864. Al respecto, la mayoría de los analistas coinciden en señalar el nacimiento de las relaciones internacionales o de la constitución de una sociedad internacional con la Paz de Westfalia, en tanto espacio de negociación política entre potencias y otras unidades con cierto grado de autonomía de Europa, donde se instala el estatus de Estado nacional. Sin desconocer ni dejar de investigar las interrelaciones entre centros de poder independientes -tribus, clanes, hordas, ciudades-Estado, principados, etc.- en variadas prácticas de coordinación o subordinación, los historiadores y teóricos de las Relaciones Internacionales comparten la idea que un espacio físico y sociojurídico que pueda denominarse como internacional, solo tiene sustento si se define un espacio físico y sociojurídico interno o doméstico. Así, se argumenta que los dos tratados de 1648, efectivamente, descartan la idea de una Europa unitaria y monolítica e inauguran un sistema interestatal basado en: el principio de igualdad jurídica, con un sistema laico de Estados independientes; el principio de soberanía por el cual el régimen político o la orientación religiosa de cada unidad nacional es indiferente de su estatus como centro independiente; el principio de equilibrio de poder por la generación de una nueva estructura internacional en base a Estados que conviven en un sistema internacional sin un poder coactivo central.

\section{Problematización}

Para los teóricos de las Relaciones Internacionales, sobre todo los que desarrollan sus investigaciones desde un nivel de análisis sistémico considerando a los Estados, y principalmente las grandes potencias como los actores centrales del sistema, la relación entre estructura de poder, conflictividad del sistema y construcción de órdenes internacionales, han sido problemas centrales 
de investigación. Entre este cuerpo de teorías se encuentran: las teorías del equilibrio de poder; las teorías de la hegemonía; la teoría de la paz democrática; la teoría de la sociedad internacional.

Entre las teorías del equilibrio de poder, la teoría realista clásica plantea que el equilibrio de poder multipolar es la configuración estructural más favorable a la paz (Morgenthau, 1986 [1948]; Kissinger, 1973), mientras que los teóricos neorrealistas consideran que la configuración bipolar favorece la estabilidad (Waltz, 1988; Mearsheimer, 2001). Incluso, si este equilibrio bipolar es reforzado con la existencia de armas nucleares, el sistema adquiere mayor estabilidad (Jervis, 1989; Waltz, 2003). Por su parte, los teóricos de la hegemonía conciben que el sistema internacional más estable y pacífico, resulta de un poder hegemónico (Gilplin, 1981; Kennedy, 2006 [1994]). Específicamente, los teóricos de la transición de poder plantearon que la conflictividad tenderá a aumentar cuando el sistema se encuentre en fase de transición (Organski y Kugler, 1980; Tammen, 2000; Lemke, 2002). ${ }^{1}$ Modelski (1987) y Goldstein (1988), enunciaron que los períodos de mayor conflictividad se caracterizan por el desencadenamiento de guerras de alcance global entre potencias que disputan por la hegemonía. Por su parte Doran (1991), postuló que cuando más de una gran potencia se sitúa en puntos críticos de ascenso y declive en su proceso evolutivo, se acrecientan las probabilidades de guerras sistémicas.

En el marco de la tradición liberal han sido los teóricos de la paz democrática los de mayor talante estado-céntrico. Sus investigaciones se sientan sobre tres proposiciones: 1. las democracias son más pacíficas que las autocracias; 2. las relaciones entre democracias son más pacíficas que las relaciones entre democracias y autocracias, o entre autocracias; 3. la expansión de las democracias tiene efectos pacificadores en el sistema internacional. La tercera proposición es la que se inscribe en el nivel de análisis sistémico. En este nivel, los hallazgos científicos hasta el momento han mostrado que de existir una relación entre prevalencia de la democracia y de la guerra en el sistema, la misma es de tipo no-lineal. Ello supone que la expansión de democracias en el sistema puede comenzar a tener efectos pacificadores una vez que alcancen y superen cierto umbral de prevalencia (Gleditsch y Hegre, 1997) ${ }^{2}$.

Por su parte, en el marco de las teorías de la sociedad internacional, la teoría típicamente estado-céntrica ha sido la desarrollada por la escuela inglesa de las relaciones internacionales (Wight, 1977; Bull, 2005 [1977]). Desde esta perspectiva, si bien el orden internacional contemporáneo presenta una base sociopolítica común, no presenta una base sociocultural común. Es por ello que los teóricos conciben a la sociedad internacional contemporánea como un sistema internacional. Dos mecanismos son los que permiten preservar el orden en el sistema internacional contemporáneo. Uno de ellos es el equilibrio de poder. Mediante este mecanismo se preserva el sistema de Estados y se evita el surgimiento de imperios que pongan en cuestión el principio ordenador estado-céntrico. El segundo es el Derecho Internacional; éste tiene la funcionalidad de regular las relaciones entre Estados mediante instituciones descentralizadas y coercitivas, en un esquema en el que incluso la amenaza de recurrir a la guerra es siempre una posibilidad (Bull, 2005 [1977], pp. 105-126).

En lo que respecta a conflictividad, no existe acuerdo entre los científicos sobre qué es y cómo medirla. Han sido los investigadores cuantitativos de la guerra los primeros que trataron de aproximarse a su estudio. Algunos de ellos han estudiado la proporción de años que el sistema registró guerras (Woods y Baltzly, 1915). Otros lo han hecho a partir del estudio de las frecuencias de guerras interestatales en el sistema (Richardson, 1960; Denton y Warren, 1968). Otra forma de aproximación ha sido a través del estudio de tendencias en lo que respecta a severidad o letalidad de las guerras (Wrigth, 1965). Por último, otros autores se han aproximado a su estudio dando cuenta de distintas dimensiones de las guerras entre grandes potencias. Entre estas dimensiones se encuentran: frecuencia, magnitud, severidad, concentración (Levy, 1983). Ahora bien, teniendo

\footnotetext{
${ }^{1}$ Para estos teóricos, el sistema internacional se encuentra en fase de transición cuando se cumplen los siguientes requisitos: declive de una potencia hegemónica, ascenso de una potencia desafiante y cuestionamientos al orden internacional por parte de la potencia desafiante.

${ }^{2}$ Algunos investigadores han aportado evidencias que es a partir del umbral del $40 \%$ de prevalencia, que las democracias comienzan a tener efectos pacificadores en el sistema (McLaughlin, 1999; 2012).
} 
en cuenta lo expuesto, ¿cómo ha sido la evolución en los niveles de conflictividad del sistema teniendo en cuenta su tipo de estructura o, dicho de otra manera, su número de grandes potencias? ¿De qué manera, los ordenamientos internacionales de Westfalia, Viena, Versalles y San Francisco han sido funcionales a los intereses de los Estados con mayores capacidades del sistema internacional? Para aportar respuestas, se presenta a continuación la estrategia de investigación.

\section{Estrategia de investigación}

La investigación se sustenta en la combinación de tipos de estudio descriptivo e interpretativo. La respuesta a la primera de las preguntas planteadas se basa en conocer las tendencias de la estructura del sistema internacional contemporáneo y sus niveles de conflictividad. Por su parte, la respuesta a la segunda pregunta se sustenta en la aplicación de una estrategia narrativa orientada a interpretar las respuestas normativas de las instituciones jurídicas de la comunidad internacional en las cumbres ordenadoras del sistema internacional. En lo que respecta a la dimensión descriptiva, lo primero que se realiza es un abordaje cuantitativo de los niveles de conflictividad de las guerras entre potencias que se libraron en el período 1500-2000. Para ello, se construye un índice de conflictividad a partir de una serie de propiedades básicas de los conflictos bélicos: 1 . el número de grandes potencias participantes en conflictos bélicos; 2 . la severidad, entendida por el número de muertes por conflictos bélicos entre potencias; 3 . la duración de los conflictos bélicos entre potencias. Dado que las tres variables ofrecen unidades de medidas diferentes, en primera instancia las variables serán normalizadas mediante la técnica estadística de puntuaciones z. Seguidamente, para construir el índice los valores z de cada variable fueron agregados de forma aditiva y divididos por el número de variables. ${ }^{3}$ A continuación se especifica la fórmula para su cálculo.

$$
\operatorname{Cgp}=\frac{z A p t+D p t+z S p t}{3}
$$

$\operatorname{Cgp}=$ Conflictividad de las guerras entre potencias mundiales $z A p t=$ Puntuación $z$ del alcance de las guerras entre potencias $z D p t=$ Puntuación $z$ de la duración de las guerras entre potencias $z$ Spt $=$ Puntuación $z$ de la severidad de las guerras entre potencias

$$
3=\text { Número de variables }
$$

Posteriormente, para avanzar en la identificación de las tendencias de la conflictividad del sistema, se realiza la fragmentación del sistema internacional en veinte períodos de veinticinco años cada uno, representativos del período 1500-2000. Sobre la estructura del sistema internacional, existe acuerdo entre los teóricos de las Relaciones Internacionales de que la misma está condicionada por el número de grandes potencias del sistema. En tal sentido, tradicionalmente se han identificado tres grandes tipos de estructuras: unipolar, bipolar, multipolar. En este estudio, se propone una clasificación levemente diferente, identificando cuatro tipos de estructuras: unipolar, cuando el sistema registra entre uno y dos potencias; bipolar, entre dos y tres; multipolar moderada, entre tres y cinco; multipolar alta, entre cinco y más. ${ }^{4}$ En lo que respecta a la variable conflictividad aplicada al sistema internacional, lo que se realizará son ajustes al índice de conflictividad aplicado a los conflictos bélicos. En ese sentido, el índice se compone de las siguientes variables: 1 . alcance promedio de guerras entre grandes potencias por período; 2. duración promedio de guerras entre potencias por período; 3. severidad promedio de

\footnotetext{
${ }^{3}$ Para generar los datos correspondientes a cada uno de estas variables implicadas en el Índice de Conflictividad, se han utilizado como fuentes de datos la obra de Levy (1983) y el estudio de Sarkees y Wayman (2010) en el marco del proyecto de Correlatos de Guerra.

${ }^{4}$ Para aportar evidencias sobre las tendencias de la estructura de poder, se apelará a los datos contenidos en la obra de Jack Levy (1983) y al banco de datos del Índice de Capacidades Materiales (cinc) en su versión 4.0 del proyecto de Correlatos de Guerra. A través de la obra de Jack Levy es posible identificar el número de grandes potencias en el período 1500-1950, al tiempo que el Índice de Capacidades Materiales 4.0, ofrece información cuantitativa que permite identificar el número de grandes potencias del sistema en el período 1950-2000.
} 
las guerras entre grandes potencias por período. ${ }^{5}$ Nuevamente, dado que las tres variables ofrecen unidades de medidas diferentes, en primera instancia las variables fueron normalizadas mediante la técnica estadística de puntuaciones z. Seguidamente, para construir el índice los valores z de cada variable fueron agregados de forma aditiva y divididos por el número de variables. ${ }^{6}$

$$
\text { Cspt }=\frac{z A p t+D p t+z S p t}{3}
$$

Cspt $=$ Conflictividad del sistema político internacional de las grands potencias en tiempo $\mathrm{t}$ $z A p t=$ Puntuación $z$ del alcance promedio de las guerras entre potencias en tiempo $t$ $z D p t=$ Puntuación $z$ de la duración promedio de las guerras entre potencias en tiempo $t$ $z S p t=$ Puntuación $z$ de la severidad promedio de las guerras entre potencias en tiempo $t$ $3=$ Número de variables

Por su parte, a los efectos de desarrollar el estudio en su dimensión interpretativa, la investigación se centra desde una perspectiva hermenéutica y funcionalista. En ese sentido se parte de la premisa de que todos los hechos sociales contienen inherentemente significados y, por tanto, son pasibles de interpretaciones. En este caso en particular se procura dar cuenta que los órdenes internacionales construidos en Westfalia, Viena, Versalles y San Francisco, pretendieron ser funcionales a las potencias vencedoras. La interpretación de dicho orden se sustenta en la evolución de tres mecanismos específicos: igualdad jurídica, principio de soberanía y equilibrio de poder. En ese sentido, la interpretación de estas cumbres se realizará desde una perspectiva comparativa en la que cada una de estas Cumbres constituye la unidad de análisis, comparando las mismas mediante la interpretación de los tres mecanismos específicos mencionados.

\section{Resultados de la investigación}

A continuación, se presentan los resultados del estudio en dos partes, las cuales están orientadas a dar respuestas a las dos preguntas de investigación. En este sentido, la primera parte está orientada a aportar evidencia cuantitativa sobre la evolución de la frecuencia y conflictividad de la guerra entre potencias, la estructura del sistema y sus niveles de conflictividad. La segunda parte estará orientada a interpretar la relación de dependencia de los órdenes mundiales con los grandes poderes del sistema en los momentos en que los mismos fueron concebidos.

\subsection{Estructura y conflictividad}

En función de la combinación de datos suministrados en Levy (1983) y Sarkees y Wayman (2010), durante el período ha sido posible identificar sesenta guerras interestatales entre grandes potencias. Solo cuatro de ellas registran niveles de conflictividad superiores a la media histórica en los niveles de conflictividad $(0,00)$. Estas guerras fueron: la Segunda Guerra Mundial, con un nivel de conflictividad de 2,96; la Guerra de los Treinta Años, en la que la conflictividad muestra un valor de 2,51; la Primera Guerra Mundial con un índice de conflictividad de 2,17; las Guerras Napoleónicas con niveles de conflictividad de 1,25. Los resultados de la aplicación del índice se encuentran en anexo. Los resultados ofrecidos confirman que los ordenamientos

\footnotetext{
${ }^{5}$ Sobre la base de datos sistematizados por Levy, el alcance promedio por período fue calculado de la siguiente forma: sumatoria del número de potencias en guerra entre sí por período, dividido la sumatoria de inicios de guerras entre potencias por período. La duración promedio por período responde al siguiente cálculo: sumatoria de años de cada guerra entre potencias por período, dividido la sumatoria de inicios de guerra entre potencias por período. Por su parte, la severidad promedio fue calculada de la siguiente manera: sumatoria de muertes por conflictos activos por período, dividido el número de conflictos activos por período.

${ }^{6}$ Para generar los datos correspondientes a cada uno de estas variables implicadas en el Índice de Conflictividad, se han utilizado como fuentes de datos la obra de Levy (1983) y el estudio de Sarkees y Wayman (2010) en el marco del proyecto de Correlatos de Guerra.
} 
internacionales de Westfalia, Viena, Versalles y San Francisco, fueron precedidos por los conflictos bélicos entre potencias que mayores niveles de conflictividad registraron. El gráfico 1 ilustra la frecuencia y la conflictividad de las guerras interestatales entre grandes potencias en el período 1500-2000.

Conflictividad de las guerras entre G. Potencias 1500-2000

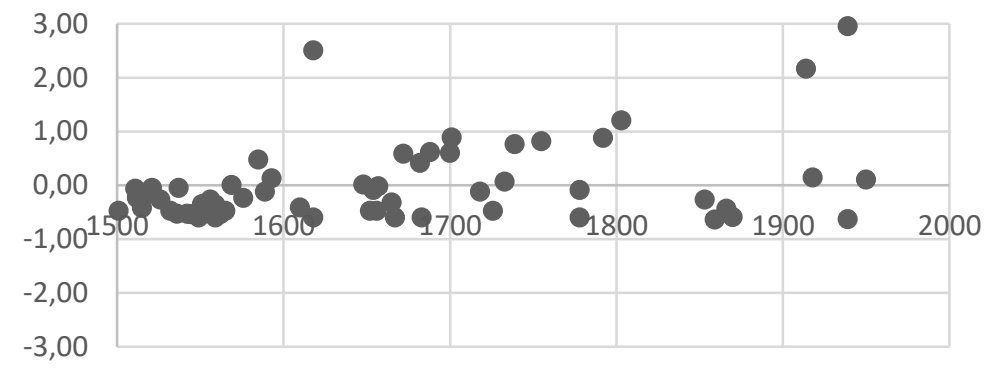

Fuente: elaboración propia

En lo que respecta a la estructura de poder del sistema internacional, lo que ha predominado en el transcurso de los quinientos años considerados ha sido un tipo de estructura multipolar. En 11 de los 20 períodos el sistema registró una estructura multipolar elevada, en ocho períodos una estructura multipolar moderada y en un solo período una estructura bipolar. En los quinientos años considerados, no se identifican períodos en los que el sistema registre una estructura unipolar, lo que contradice los postulados centrales de los teóricos de la hegemonía. El gráfico 1 ilustra las tendencias de la estructura de poder durante el período considerado.

Evolución del número de grandes potencias del sistema internacional 1500 - 2000

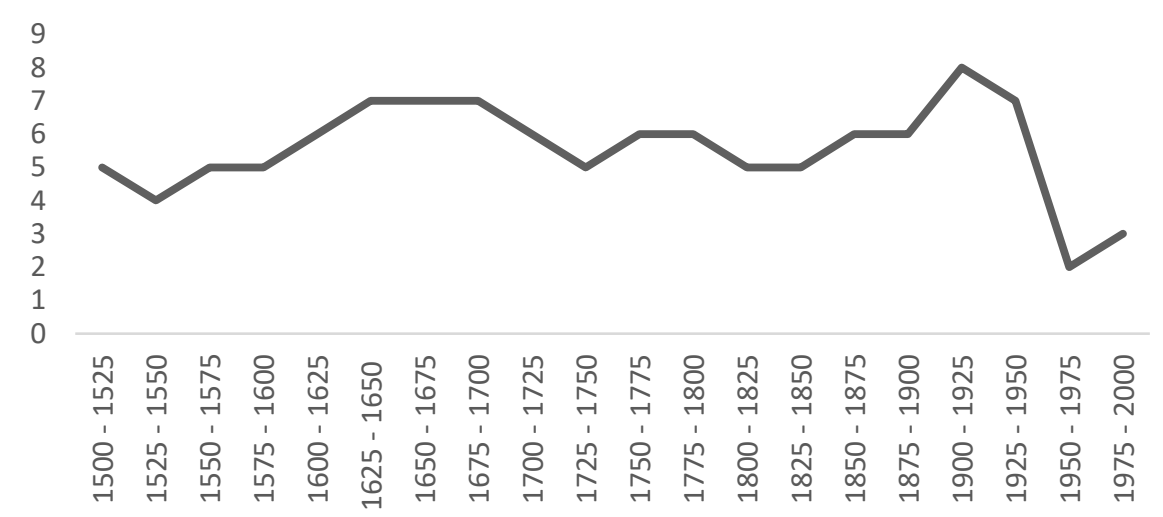

Fuente: elaboración propia

Por su parte, en lo que respecta a la conflictividad del sistema internacional durante el período, los resultados evidencian que, en cuatro períodos específicos, el sistema registró elevados niveles de conflictividad. Los períodos de mayor conflictividad del sistema fueron cuatro: 16251650, en el que se desarrolló la Guerra de los Treinta Años; 1800-1825, en el que se desarrollaron las Guerras Napoleónicas que culminaron en 1815; los dos transcurridos en la primera mitad del siglo XX, 1900-1925 y 1925-1950, cuando se dieron rivalidades, alianzas y conflictos que derivaron en las guerras mundiales (1914-1919 y 1939-1945). En anexo se presentan los datos que dan cuenta de la evolución de la conflictividad en el sistema internacional. El siguiente gráfico ilustra las tendencias de la conflictividad en el sistema internacional en el período 1500-2000. 
Tendencia de la conflictividad en el sistema internacional G. potencias 1500-2000

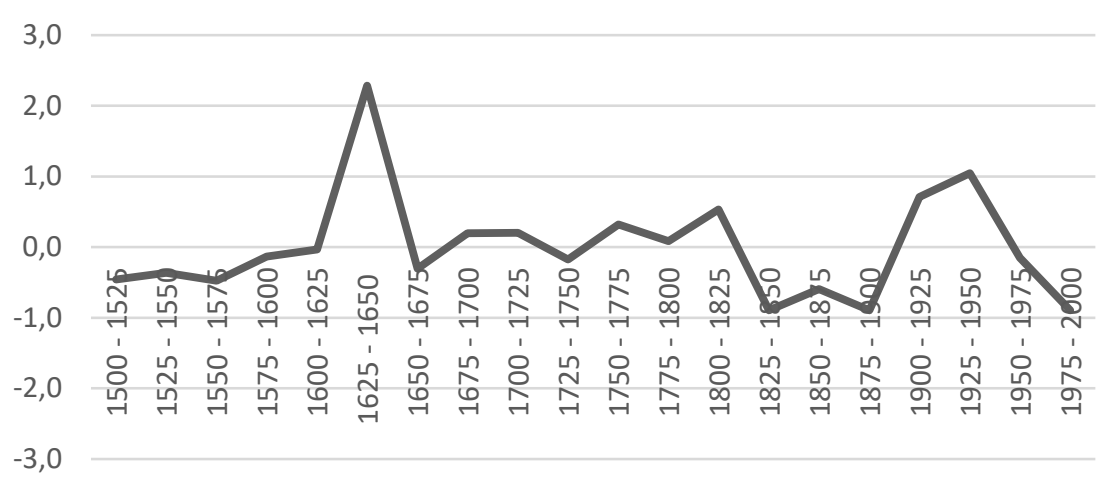

Fuente: elaboración propia

\subsection{Las cumbres y la evolución de los principios}

\subsubsection{Soberanía}

El principio de la soberanía de los Estados nacionales no encuentra una consagración expresa en las disposiciones de los tratados emanados de la Paz de Westfalia en 1648. No obstante, dicho principio, junto al de la igualdad jurídica, es el sustento ideológico y el presupuesto lógico sobre el que se edifica todo el sistema consagrado. La prueba de esta afirmación radica en la nueva estructura que se le da al espacio europeo, basada en la convivencia de una pluralidad de Estados, y el reconocimiento de autonomía a las unidades pequeñas como los Países Bajos, los Cantones Suizos y, sobre todo, los Estados alemanes.

La tan mentada afirmación sobre la calidad constitutiva del principio de soberanía es discutida por el jurista uruguayo Felipe Paolillo (1993, pp. 170-171), quien recordaba que, en Europa Occidental, antes del Congreso, operaba un reconocimiento tácito a una serie de soberanías estatales centralizadas por regímenes absolutos: España a partir de la unión de Castilla y Aragón (1469); Inglaterra a partir de la Guerra de las Dos Rosas (1485) y Francia a partir de la Guerra de los Cien Años (1453). Así, la soberanía era entendida como poder supremo en el espacio doméstico, sujeta al derecho divino, y como independencia en el espacio externo, sujeta al Derecho Internacional, en tanto precario conjunto de reglas en el que el sujeto obligado siempre contribuye a la consagración de la norma. ¿En qué consiste, entonces, la innovación de los tratados de Westfalia con respecto al principio de soberanía? En primer lugar, en la legitimación del principio en un espacio multilateral y representativo del orden sub-sistémico europeo contemporáneo, con negociadores provenientes de Estados que, ostentando diferentes capacidades, mostraron la firme voluntad de reconocerse recíprocamente como unidades soberanas. En segundo lugar, y si bien se mantiene el valor absoluto del principio al interior de cada frontera nacional, en la consagración como una limitante en las relaciones exteriores, tanto por el respeto a otras soberanías estatales como por la observancia a las normas del Derecho Internacional. Sin embargo, el también jurista uruguayo Alberto Domínguez Cámpora (1947, pp. 25-26) advertía que, en cuanto a las relaciones domésticas entre gobernantes y gobernados, continúa una subordinación contraria a la libertad individual, ya que se consagra la potestad del príncipe de elegir la religión de los súbditos -Cujus regio, ejus religio-, quedando solo la salvaguarda del derecho de emigrar a Estados donde otro príncipe imponga la religión por ellos practicada.

Así, los tratados de Westfalia suponen la supresión de dos reivindicaciones sobre jurisdicción territorial: las patrimonialistas, feudales o hereditarias, y la legitimada en el precepto 
de la universalidad cristiana, por la que el emperador o el papa ostentaban la potestad de intervenir en asuntos que consideraran atinentes a la cristiandad en cualquier unidad nacional. Como consecuencia, queda proclamado un primer esbozo del principio de no intervención de poderes temporales o divinos en los asuntos internos de los Estados. En adelante, la soberanía queda confirmada desde dos dimensiones. Una interna como sinónimo de supremacía de un gobierno central sobre la población en su respectiva jurisdicción territorial, desplazando otros ordenamientos domésticos; esto implica una atribución de funciones con el objetivo de satisfacer los fines nacionales. Y una dimensión externa como sinónimo de independencia e igualdad jurídica a partir de una supremacía que, al desplazar esos otros ordenamientos domésticos, se proyecta al sistema internacional como único interlocutor válido de esa unidad nacional.

Para comprender el valor asignado al principio de soberanía e, incluso, al de igualdad jurídica entre Estados en el Congreso de Viena, es necesario aprehender la esencia del orden que se intentó establecer a partir de $1815 \mathrm{y}$, sobre todo, su sustento ideológico diametralmente opuesto al establecido en Westfalia. En efecto, el Acta Final del Congreso constituye un verdadero ejemplo de paradigma restaurador. El supuesto ideológico secular de Westfalia también es permeado en forma dramática, ya que la Santa Alianza surgió bajo la influencia del zar Alejandro I, quien transmitió su espíritu místico. Así, el preámbulo del Tratado de la Santa Alianza, advierte "su decisión inquebrantable de no tomar otra regla de conducta, sea en la administración de los Estados o en la política internacional, que los preceptos de paz y caridad de la religión de Cristo". En suma, los monarcas se considerarán como hermanos y compatriotas, comprometiéndose a prestarse asistencia mutua e irrestricta; una especie de "sindicato de monarcas" dispuesto a practicar una política intervencionista y siempre contraria al derecho de los pueblos a su autodeterminación (Domínguez Cámpora, 1947, p. 38).

A partir del sistema de Estados instaurado en 1648, la necesidad de comprobación de que un gobierno goza del atributo de la soberanía fue generando en el Derecho Internacional el instituto de reconocimiento de gobierno, en tanto reglas objetivas para darle cauce a una herramienta fundamental de política internacional. Así, la práctica de los Estados fue consagrando normas consuetudinarias a partir de experiencias extraídas de etapas históricas decisivas. En concreto, todo gobierno efectivo, estable, responsable con los compromisos contraídos por su Estado, e independiente, agota los requisitos para su reconocimiento. Y la llamada tesis jurídica del reconocimiento, se inclina por la no pertinencia de evaluar el régimen político o el régimen de gobierno que se instala, ni la forma en que procedió dicha instalación, salvo en lo referido a la intervención extranjera o a la violación de los principios y normas sobre el uso de la fuerza. Como consecuencia, la posición mayoritaria de los doctrinos coincide en señalar como contrario a derecho el llamado legitimismo, que proclama el no reconocimiento de regímenes surgidos por la fuerza y que conoció dos formatos históricos: el monárquico como pacto político en 1815 y el constitucional o democrático de la Doctrina (Carlos R.) Tobar de 1907. La primera forma histórica proclama el no reconocimiento de gobiernos surgidos en contra de alguna de las monarquías establecidas, en rechazo a cualquier sustitución por regímenes de vocación revolucionaria. La segunda, elaborada por el entonces canciller ecuatoriano, sostiene el no reconocimiento de gobiernos surgidos por quebrantamientos de normas constitucionales del Estado en cuestión, en procura de preservar el régimen democrático (Jiménez de Aréchaga, 1995, pp. 45-83).

Finalmente, cabe reflexionar sobre la naturaleza del pacto entre monarquías que opera a partir de 1815. Renouvin (1990, p. 41) coincide en que el concierto de las cuatro grandes potencias -Rusia, Gran Bretaña, Austria y Prusia- implicaba la idea de un control acordado y dirigido a mantener la paz. El rasgo de control es revelado por la innovación más notable del punto de vista de la negociación, con la instauración de conferencias periódicas, lo que supuso no limitar los contactos multilaterales a intercambios de notas, involucrando a los funcionarios responsables de la política exterior con reuniones directas. Kinder y Hilgemann (1990, p. 41) califican su resultado como la primera organización supranacional de la época moderna, con fundamento y base ideológica radicada en una alianza entre el altar y el trono, con el objetivo de mantener el statu quo social, económico y político. Por el contrario, Renouvin (1990, p. 41) concluye que no hay en los textos constitutivos, instrumentos que impliquen una cesión de soberanía de los Estados, 
no hay un mecanismo superior que organice una protección mutua de la integridad territorial, no hay un compromiso recíproco de renunciar a la guerra. En definitiva, respondiendo al objetivo de confirmar la preponderancia de grandes potencias victoriosas, se instrumentó un mero directorio de gendarmes, en una apuesta lejana a una organización política inspirada en ideas federativas.

La Conferencia de Paz de París de 1919 y la constitución de la Liga de las Naciones, suponen un punto de inflexión con relación a las cumbres multilaterales ordenadoras del sistema internacional, al inaugurar dos nuevas tensiones. La primera supone un equilibrio institucional y político entre las potestades atribuidas a una Organización Internacional con fines generales y de alcance geográfico universal con los intereses soberanos de los Estados. La segunda tensión estriba en la armonización entre un nuevo diseño sistémico internacional basado en la observancia a principios liberales y democráticos con el derecho a la libre determinación de los pueblos. Sobre esta segunda tensión, Neila Hernández et al. (2018, p. 160) explican que, si bien el triunfo militar correspondió a las llamadas potencias democráticas y liberales, las que intentaron expandir sus principios y concepciones, el desgaste experimentado en la guerra y las dificultades en las negociaciones de paz, entre otras razones, abonaría el terreno para proyectos totalitarios "de diferente signo", tanto en el propio desarrollo de la guerra como en la precaria paz de la posguerra. De todas formas, la expansión de principios y concepciones propios de un sistema político interno como guía para las relaciones internacionales constituye, en sí misma, una afectación al principio de soberanía tal como se consagró en los tratados de Westfalia.

El período histórico de la post Primera Guerra Mundial evidencia una nueva concepción sobre el principio de soberanía que también transciende, e incluso afecta, el protagonismo exclusivo de los Estados nacionales de la restricta concepción westfaliana: el derecho al reconocimiento de las nacionalidades y minorías nacionales. En concreto, el principio de la libre determinación de los pueblos, su invocación y satisfacción, había sido utilizado como arma propagandística por ambos bandos durante el conflicto bélico. En particular, los aliados vencedores contemplaron principalmente a polacos, checos y serbios. Por eso, claves del hinduismo y del islam, formulaciones como el panarabismo, el nacionalismo árabe, el panislamismo y el panafricanismo, también conformaron el contexto de las negociaciones. (Neila Hernández et al., 2018, p. 170).

En concordancia, a partir de 1919, la creación de una Organización Internacional, hallaba correspondencia con un nuevo sistema internacional basado en este principio de autodeterminación que, en esencia, significaba un rechazo a cualquier forma de colonialismo, rechazo que solo podía ser liderado y garantizado por la Liga de las Naciones. Si bien la expansión mediante dominio colonial siguió vigente en los tratados derivados de la Conferencia de Paz, con una redistribución que premió a los vencedores, su presencia en estos territorios sería cada vez más contestada en una consecuencia del despertar de la conciencia nacional a partir de la participación en la guerra. El novel mecanismo creado en el esquema institucional de la Liga, consistirá en un régimen de mandato, fórmula jurídica que somete a un territorio y a una población bajo la jurisdicción de un sujeto de Derecho Internacional, distinto a los Estados nacionales y representativo de una voluntad multilateral.

Finalmente, la Conferencia de San Francisco y la consagración de la Carta de las Naciones Unidas en 1945 suponen un hito con relación a los principios de Derecho Internacional. Para el notable jurista uruguayo, especialista en el sistema de las Naciones Unidas, Eduardo Jiménez de Aréchaga (1980, p. 107), la inclusión de una enumeración específica sobre propósitos y principios, que ordena obligaciones de conducta para miembros y reglas de funcionamiento para la Organización, constituye: "La más notable innovación de la Carta [...] comparada con el Pacto de la Liga de las Naciones". Incluso a partir de 1945, la Organización de las Naciones Unidas prosiguió con los esfuerzos de codificación de los principios en su Comisión de Derecho Internacional. Así, después de siete años de trabajo por parte de un Comité Especial, donde estaban representados todos los grupos y tendencias de la Organización, se aprueba por unanimidad en la Asamblea General, la Resolución N 2625 en 1970, "Declaración sobre los 
principios de Derecho Internacional referentes a las relaciones de amistad y a la cooperación entre los Estados de conformidad con la Carta de las Naciones Unidas".

Específicamente, el jurista español Manuel Diez de Velazco (1990, p. 145) sostiene que la proclamación de la igualdad soberana del artículo 2 parágrafo 1 , contiene dos aspectos interrelacionados: la propia proclamación de la igualdad jurídica y la proclamación del principio de soberanía, al determinar, simplemente, que "La Organización está basada en el principio de la igualdad soberana de todos sus Miembros". Jiménez de Aréchaga (2010, p. 159) agrega que la Carta contiene una alusión implícita al principio de soberanía y a su corolario, el derecho de no intervención. En primer lugar, porque la proclamación de la igualdad soberana conlleva la prohibición de un Estado de hacer injerencia en los asuntos de otro. En segundo lugar, por lo dispuesto en el artículo 2 parágrafo 7, cuando se advierte que: "Ninguna disposición de esta Carta autorizará a las Naciones Unidas a intervenir en los asuntos que son esencialmente de la jurisdicción interna de los Estados, ni obligará a los Miembros a someter dichos asuntos a procedimientos de arreglo conforme a la presente Carta; pero este principio no se opone a la aplicación de las medidas coercitivas prescritas en el Capítulo VII”. El jurista uruguayo explica que, en forma consecuente, la Organización no puede permitir a los Estados hacer lo que se prohíbe a sí misma; por lo tanto "tal prohibición debe extenderse a fortiori ${ }^{7}$ a los Estados miembros en sus relaciones con otros Estados."

El también jurista español Juan Antonio Carrillo Salcedo (1987, p. 11) analiza la Conferencia bajo el supuesto de compromisos políticos que quedaron incorporados en la Carta. Uno de ellos, supuso el "delicado equilibrio" entre las aspiraciones de independencia de los pueblos y territorios sometidos a dominación colonial con los intereses estratégicos, políticos y económicos de las grandes potencias coloniales. En concreto, el principio general de libre determinación de los pueblos tiene una primera mención explícita en la Carta cuando el artículo 1 parágrafo 2 señala como propósito de la Organización: "Fomentar entre las naciones relaciones de amistad basadas en el respeto al principio de la igualdad de derechos y al de la libre determinación de los pueblos, y tomar otras medidas adecuadas para fortalecer la paz universal". No obstante, el principio no es incluido en el artículo 2, en la histórica enumeración de principios.

Posteriormente, en 1960, la Resolución de la Asamblea General 1514 (XV) titulada "Declaración sobre la concesión de la independencia a los países y pueblos coloniales", consagrará ese derecho de libre determinación de los pueblos que incluye su estatuto político, su desarrollo económico, social y cultural, y el fin del colonialismo. Inclusive en 1961, la Resolución 1654 (XVI) establece un comité encargado de vigilar el cumplimiento de la 1514. Pero, en definitiva, la Resolución 2625 contempla el principio de la igualdad de derechos y de la libre determinación de los pueblos y advierte que este último no puede interpretarse en el sentido de autorizar o fomentar cualquier acción encaminada a quebrantar o menospreciar, total o parcialmente, la integridad territorial de Estados soberanos e independientes.

\subsubsection{Igualdad jurídica}

La Paz de Westfalia se revela ante la historia como la primera cumbre multilateral que agrupa un importante número de unidades europeas que, al momento de iniciarse las negociaciones, exhibían algún grado de autonomía. Si bien queda claro que este concepto fundante de igualdad jurídica presenta enormes limitaciones, sobre todo en lo que refiere a las adjudicaciones territoriales posteriores a la Guerra de los Treinta Años, los alcances de las disposiciones de los tratados abarcan desde pequeños Estados alemanes -algunos de ellos constituidos por un feudo- hasta unidades como Francia, Suecia, España o el propio Sacro Imperio Romano Germánico. Asimismo, si bien se trata de acuerdos que ponen fin a una guerra de carácter confesional y que enfrentó a unidades con muy diferentes regímenes políticos, las negociaciones y disposiciones comprendieron a católicos y protestantes, repúblicas y monarquías absolutas,

\footnotetext{
${ }^{7}$ Expresión en latín, tomada del lenguaje jurídico bajo la traducción "con mayor motivo".
} 
logro que hasta la cumbre hubiera sido imposible. Cabe, entonces, preguntar ¿qué se quiere expresar al afirmar o negar que en Westfalia se consagró la igualdad jurídica entre Estados?

En la academia uruguaya, mientras Domínguez Cámpora (1947, pp. 25-26) aseguraba que la respuesta reside en la demostración que, desde el punto de vista práctico, los Estados obraron todos en pie de igualdad y disfrutando de iguales derechos, Paolillo (1993, pp. 171-172) aprovechará la oportunidad para diferenciar tres dimensiones de la igualdad entre Estados: la real, la jurídica o ante el derecho y la funcional, y alegará que la consagración de las dos últimas hallan en Westfalia solo un atisbo. Evidentemente ni en Westfalia ni en ninguna cumbre de Estados en las que se evalúe las consecuencias de un gran conflicto bélico y se diseñe un escenario de futuro para contemplar los intereses de las partes, se consagra una igualdad real o absoluta de Estados, por la sencilla razón que las capacidades estatales hacen que los países partan de posicionamientos completamente distintos. La piedra fundacional instalada en 1648, abreva a una igualdad jurídica, a la igualdad que tienen los Estados frente al derecho, a la facultad de reclamar la misma protección de una norma jurídica ostentada tanto por una unidad pequeña como por una gran potencia.

Paolillo (1993, p. 172) explica que lo más notorio de esta manifestación de igualdad jurídica fue el reconocimiento de pequeños Estados alemanes con el derecho a ser libres, independientes y convivir en igualdad de condiciones con las grandes potencias europeas pero, sobre todo, con el derecho de determinar la religión en su jurisdicción. En definitiva "[resulta] evidente que hubo una importante manifestación de igualdad jurídica, porque se buscó crear un estatuto jurídico, en el cual los Estados, a pesar de sus diferencias reales, tuvieran igual derecho a su independencia, a su soberanía". Sin embargo, y paradójicamente, ese mismo reconocimiento es la demostración de esa profunda desigualdad real. En efecto, la creación de los pequeños Estados alemanes, si bien contempló las aspiraciones de sus poblaciones, evidencia la intención de Francia de debilitar al Sacro Imperio Romano Germánico. Finalmente, el autor argumenta que no hubo tampoco una total igualdad funcional, porque a algunos Estados, como Portugal representado por Francia-, no se les permitió opinar ni votar. De todas formas, este concepto de igualdad funcional solo tendrá una manifestación, más o menos acorde, a partir de la creación de Organismos Internacionales de alcance geográfico universal y fines generales, y más precisamente con la Carta de las Naciones Unidas.

No se puede comprender el escaso valor asignado al principio de igualdad jurídica en las negociaciones ni las consecuencias del Congreso de Viena, sin insistir en que el presupuesto ideológico que impulsa a sus signatarios reside en cerrar un pacto político de corte restaurador como sustento de una alianza permanente entre vencedores con el objetivo de consolidar un nuevo orden sobre la base de una forma de gobierno. Este elemento común hizo viable la constitución posterior de la Santa Alianza (setiembre de 1815) y la Cuádruple Alianza (noviembre de 1815).

Con relación al principio analizado en este apartado, Paolillo (1993, p. 24) destaca un detalle preliminar y revelador: el Congreso nunca funcionó como un plenario, salvo en la instancia de la firma del Acta Final. Las cuatro grandes potencias negociaron entre ellas sin considerar como contrapartes a los pequeños y medianos Estados, particularmente en la discusión del problema principal: el estatus y la división de Polonia y Sajonia. No obstante, en los demás temas, se constituyeron diez comités de conformación plural entre los que se destaca el de ríos internacionales, el de precedencia diplomática, el de asuntos alemanes y el de comercio de esclavos. En este contexto, cabe resaltar el pedido de Gran Bretaña, para darle mayor participación a España, Portugal y Suecia. En definitiva, el Acta Final del Congreso es firmada por los plenipotenciarios de Austria, Francia, Gran Bretaña, Portugal, Prusia, Rusia y Suecia; el rey de España dilató su accesión hasta el 7 de mayo de 1817.

Así, en un contexto de negociación en el que las discusiones se desarrollaron en forma empírica y sin método, remarcando la profunda desigualdad real y con resoluciones ad hoc que de alguna manera abrevan a una desigualdad funcional, es difícil sostener que la igualdad jurídica fuera contemplada. Al respecto, la jurista uruguaya Vilma Veida (1993, p. 37) sostiene que tanto el Congreso de Viena como el mecanismo de la Cuádruple Alianza, renuevan la diferencia entre 
grandes y pequeños Estados y, como consecuencia, se crea "una oligarquía de gendarmes en Europa" que condiciona el éxito de su acción a su reducido número de integrantes, excluyendo a las pequeñas potencias de una participación activa.

En definitiva, los esfuerzos de los vencedores que comparecieron en el Congreso y su afán por restablecer y consolidar un nuevo orden, incluso previendo el uso de la fuerza mediante mecanismos coercitivos, socavaron el núcleo acordado en Westfalia. La igualdad jurídica es afectada en tanto la independencia y la soberanía son condicionadas a adoptar, o en el mejor de los casos a no poner en peligro, el régimen político monárquico.

A pesar del contexto y la naturaleza tan disímiles entre la Conferencia de Paz de París y el cónclave de monarquías del Congreso de Viena, el signo de las negociaciones en la post Primera Guerra Mundial, sigue siendo la exclusión de las partes en la negociación, en una primera manifestación que demuestra la desigualdad real, consagra una desigualdad funcional y atenta contra la igualdad jurídica. En efecto, Francia, Gran Bretaña, Italia y Estados Unidos de América prescinden en la propia cumbre, de Alemania, Austria-Hungría, Bulgaria y Turquía, forzándolos a firmar lo acordado. No obstante, y a diferencia de lo que se suele argumentar sobre una excesiva degradación de Alemania por parte de los aliados, desde un punto de vista estricto del principio de igualdad jurídica, su personalidad internacional tuvo que ser contemplada por vía de los hechos. Su subsistencia, se constituyó en condición necesaria para cumplir con el plan de desarme y asumir las reparaciones económicas ante la ausencia de mecanismos coercitivos para forzar el cumplimiento. En los hechos, los aliados debieron tratar a Alemania en pie de igualdad, pero esto reavivaba el temor de que volviera a emerger como la potencia más fuerte de Europa. Así, se sucedieron negociaciones con presiones y amenazas, pero también con promesas y ofertas. En definitiva: "Los aliados, o algunos de entre ellos, amenazaron con estrangular a Alemania; los alemanes amenazaron con morir. Ni unos ni otros osaron llegar a los extremos" (Veida, 1993, p. 282).

Por otra parte, las investigaciones históricas coinciden en que las delegaciones tenían una vocación multilateralista como garantía de la paz, incluyendo la creación de una Organización Internacional, formulada por el presidente de Estados Unidos de América Woodrow Wilson, en 1916 y en plena guerra. En otras palabras, se abogaba para que los acuerdos derivaran en la conformación de un nuevo sistema internacional que atemperara el riesgo de una segunda conflagración mundial, en un clima de hartazgo por los conflictos armados.

En términos generales, la doctrina en Derecho Internacional señala en forma enfática que la Segunda Guerra Mundial y las violaciones a los derechos humanos en el eje nazi-fascista, terminan constituyendo la causa inmediata de los primeros esbozos de supranacionalidad con: la generación de sistemas sobre protección internacional de los derechos humanos; la idea de compromisos superiores de los Estados con normas imperativas de Derecho Internacional General -Jus Cogens-, entre las que se destaca la proscripción del uso y amenaza de la fuerzae ${ }^{8}$; el tutelaje obligatorio del Consejo de Seguridad de las Naciones Unidas ante cualquier situación susceptible de poner en peligro la paz y la seguridad internacionales (Fernández Luzuriaga y Olmedo González, 2015, p. 159-160). No obstante, la promesa del Tratado de Paz de París revela un intento normativo de inaugurar un nuevo orden que, si bien no representaba un cambio en la naturaleza interestatal de las relaciones internacionales establecida en Westfalia, esbozaba como idea rectora, alinear al sistema internacional a partir de una Organización Internacional de alcance geográfico universal y fines generales.

Aunque el alcance universal coloca a la Liga de las Naciones como un ícono en materia de regulación multilateral entre entidades en igualdad jurídica, Domínguez Cámpora (1947, p. 159-160) recuerda que, durante la Edad Media, la unidad religiosa que representaba el papado

\footnotetext{
${ }^{8}$ La Convención de Viena sobre el Derecho de los Tratados de 1969, en su artículo 53, define a esa norma imperativa de Derecho Internacional General como: "una norma aceptada y reconocida por la comunidad internacional de Estados en su conjunto como norma que no admite acuerdo en contrario y que solo puede ser modificada por una norma ulterior de Derecho Internacional General que tenga el mismo carácter".
} 
logró imponer en los Estados cristianos una serie de institutos, como "la tregua en nombre de Dios". Asimismo, los tratados de Westfalia y Viena también suponen acuerdos para regular las relaciones internacionales. No obstante, en todos estos ensayos, los Estados dominantes se arrogaron la representación de una comunidad determinada y en beneficio propio. Por el contrario, la Liga descarta la vieja matriz concertista europea que apuntaba a un "gobierno internacional de base oligárquica", que alteraba la igualdad jurídica.

En concreto, la Liga de las Naciones fue una asociación de naturaleza intergubernamental, integrada por los Estados signatarios y miembros admitidos, "Estado, Dominio o Colonia de gobierno propio" que podían ser parte del nuevo Organismo, siempre y cuando se gobernasen libremente y aceptaran los términos de la carta constitutiva. Este reconocimiento internacional a la personería jurídica de dominios o colonias, establecida en el artículo 1 numeral 2 del Pacto de la Sociedad de Naciones, derivó de las posturas de los países anglosajones. Y, como consecuencia de ese estatus, se aprobó el sistema de mandatos, en el artículo 22. Dicho artículo determina que esos pueblos confiarán la tutela a "las naciones adelantadas" que, en virtud de sus recursos, experiencia o posición geográfica son las más indicadas para asumir esa responsabilidad. La tutela "debería ser ejercida por esas naciones en calidad de mandatarios y en nombre de la Liga". En definitiva, una forma inédita de tutelar el principio de igualdad jurídica de nuevas unidades con cierto grado de autonomía en el sistema internacional.

A su vez, la estructura orgánica de la Liga se explica por el equilibrio entre una Asamblea y un Consejo. La Asamblea es un órgano plenario con reuniones anuales o reuniones convocadas por un asunto grave. El Consejo originariamente se compuso de nueve miembros, cinco permanentes y cuatro no permanentes. Los primeros miembros permanentes fueron Estados Unidos de América, Francia, Gran Bretaña, Italia y Japón. Al no ratificar el tratado, Estados Unidos de América quedó excluido y en 1926 ingresa Alemania. En 1934 salen Alemania y Japón e ingresa Rusia. Como se puede observar las membresías van dando cuenta de alianzas hasta el inicio de la Segunda Guerra Mundial. En definitiva, se constituye un directorio conformado por grandes potencias que se arrogan el derecho de decidir y que someten lo acordado a un plenario, solo a efectos de su consideración. ${ }^{9}$

Finalmente, el principio general de la igualdad soberana de los Estados es incluido literalmente en la Conferencia de San Francisco a partir de la adopción del texto de la Carta de las Naciones Unidas, cuando en el artículo 2 parágrafo 1, se determina que: "La Organización está basada en el principio de la igualdad soberana de todos sus Miembros". Como se explicara, Diez de Velazco (1990, p. 145) analiza esta disposición asegurando que el principio contiene dos aspectos relacionados entre sí: la proclamación de soberanía sobre la que se sustenta toda la Organización, aspecto ya analizado, y la proclamación de la igualdad jurídica.

Por otra parte, relevando un proceso de cristalinización del principio, el Preámbulo de la Carta, ya adelanta que la igualdad de derecho supone una facultad idéntica para poseer derechos y contraer obligaciones, y dicha facultad depende de la mera existencia del Estado y no de sus capacidades materiales, al aludir a la intención de los pueblos de las Naciones Unidas de: "reafirmar la fe en los derechos fundamentales del hombre, en la dignidad y el valor de la persona humana, en la igualdad de derechos de hombres y mujeres y de las naciones grandes y pequeñas". Como corolario también se puede decir que ningún Estado podrá ser obligado en contra de su voluntad.

No obstante, todo el sistema de Naciones Unidas solo funciona si se admite que esta igualdad jurídica no puede ser obstáculo para que todos sus Estados miembros cumplan con las obligaciones internacionales, incluso las "que derivan de aquellos tratados constitutivos de Organizaciones Internacionales que establecen una participación desigual de los Estados

\footnotetext{
${ }^{9}$ Ambos órganos responden a la máxima de un Estado, un voto. El artículo 5 del Tratado establece que: "Las decisiones adoptadas en cualquier reunión de la Asamblea o del Consejo requerirán el acuerdo de todos los miembros de la Liga representados en la reunión, excepto cuando se hubiera determinado expresamente otra cosa en este Pacto o por los términos del presente tratado".
} 
miembros en la formación de la voluntad de la Organización" (Diez de Velazco, 1990, p. 45). O sea, si se comprende la desigualdad funcional en su entramado normativo.

Para reconocer el alcance del concepto de igualdad jurídica en un sistema de desigualdad funcional que refleja la desigualdad de hecho, resulta útil analizar la regulación de los dos principales órganos de las Naciones Unidas, en cuatro dimensiones: integración, competencias, procedimiento de votación y alcance de sus resoluciones. En la primera dimensión, la Carta establece en su artículo 9 parágrafo 1 que: "La Asamblea General estará integrada por todos los Miembros de las Naciones Unidas". Además, todos los Estados miembros están representados en el órgano en un pie de igualdad. En cambio, según el artículo 23, el Consejo de Seguridad es un órgano de integración restringida, con diez miembros no permanentes -que rotan cada dos añoselegidos por la Asamblea General por dos tercios de votos, mediando iniciativa del propio Consejo de Seguridad. Pero, además, el Consejo estaba compuesto por cinco miembros permanentes China, Francia, Unión Soviética, Reino Unido y Estados Unidos de América.

La segunda dimensión radica en la temática a tratar. Si bien la Asamblea tiene una competencia genérica, ya que según el artículo 10, "podrá discutir cualesquier asuntos o cuestiones dentro de los límites de esta Carta o que se refieran a los poderes y funciones de cualquiera de los órganos creados por esta Carta[...]", el texto adelanta que "salvo lo dispuesto en el Artículo 12 podrá hacer recomendaciones sobre tales asuntos o cuestiones a los Miembros de las Naciones Unidas o al Consejo de Seguridad o a éste y a aquéllos". El artículo 12 determina que "Mientras el Consejo de Seguridad esté desempeñando las funciones que le asigna esta Carta con respecto a una controversia o situación, la Asamblea General no hará recomendación alguna sobre tal controversia o situación, a no ser que lo solicite el Consejo de Seguridad". Esta disposición se complementa con el artículo 24 parágrafo 1, piedra angular del sistema de seguridad colectiva del sistema internacional de la segunda mitad del siglo XX que instauran las principales partes negociadoras en San Francisco, al establecer que: "A fin de asegurar la acción rápida y eficaz por parte de las Naciones Unidas, sus Miembros confieren al Consejo de Seguridad la responsabilidad primordial de mantener la paz y la seguridad internacionales, y reconocen que el Consejo de Seguridad actúa a nombre de ellos al desempeñar las funciones que le impone aquella responsabilidad".

La tercera dimensión que pondera la igualad entre los miembros de la Organización debe leerse a la luz del procedimiento de votación para adoptar decisiones. En efecto, la Asamblea como órgano plenario, funciona bajo el mecanismo de un Estado, un voto. El artículo 18 parágrafo 2 especifica que "Las decisiones de la Asamblea General en cuestiones importantes se tomarán por el voto de una mayoría de dos tercios de los miembros presentes y votantes". ${ }^{10}$ A su vez, el parágrafo 3 establece que las otras cuestiones se establecerán por mayoría de presentes y votantes. En cambio, en el Consejo, no solo se establece la membrecía permanente de cinco Estados, sino que de ella deriva su derecho a interponer el veto a sus resoluciones, en toda cuestión que no sea de mero procedimiento. En concreto el artículo 27 parágrafo 3 estable que: "Las decisiones del Consejo de Seguridad sobre todas las demás cuestiones serán tomadas por el voto afirmativo de nueve miembros, incluso los votos afirmativos de todos los miembros permanentes [...]".

Finalmente, la cuarta dimensión deriva del valor jurídico de los pronunciamientos. Así, la Asamblea adopta resoluciones obligatorias solo de eficacia interna. ${ }^{11}$ Las resoluciones de

\footnotetext{
${ }^{10}$ El propio parágrafo las enumera: recomendaciones relativas al mantenimiento de la paz y la seguridad internacionales; elección de los miembros no permanentes del Consejo de Seguridad, de los miembros del Consejo Económico y Social y de los miembros del Consejo de Administración Fiduciaria; admisión, suspensión de los derechos y privilegios y expulsión de miembros; cuestiones relativas al funcionamiento del régimen de administración fiduciaria; cuestiones presupuestarias.

${ }^{11}$ Entre las principales: aceptación o expulsión de un Estado miembro; elección de miembros no permanentes para el Consejo de Seguridad, para el Consejo Económico y Social, para el Consejo de Administración Fiduciaria; elección del secretario general de la Organización; elección de los jueces de la Corte Internacional de Justicia.
} 
eficacia externa dirigidas a Estados miembros o no miembros, a Organizaciones Internacionales o a órganos del propio sistema de Naciones Unidas, no tienen carácter obligatorio. En cambio, las resoluciones del Consejo de Seguridad tienen su efecto establecido en el artículo 25 de la Carta: "Los Miembros de las Naciones Unidas convienen en aceptar y cumplir las decisiones del Consejo de Seguridad de acuerdo con esta Carta". El artículo complementa al 24, en lo que refiere a la constitución de un sistema de seguridad colectiva. Significa la consagración de un órgano con capacidad de emitir disposiciones obligatorias, incluso con potestad coercitiva y sancionatoria frente al incumplimiento de las disposiciones de la Carta.

\subsubsection{Equilibrio de poder}

Un mero análisis de las disposiciones de la Paz de Westfalia demuestra que sus negociadores, si bien proyectan con efectos multilaterales los principios de soberanía e igualdad jurídica, no atribuyeron a estos resultados utópicos que derivaran en un sistema internacional cooperativo. En definitiva, que la igualdad jurídica no disimularía diferencias de poderío real, ponderado por capacidades territoriales, demográficas, económico-comerciales y, por supuesto, militares. En este rumbo, Domínguez Cámpora (1947, p. 25-28) explicaba que en Westfalia se pusieron en juego dos clases de intereses: los políticos, consistentes en evitar el predominio del Sacro Imperio Romano Germánico, y los religiosos, impulsados por el deseo de los protestantes de sustraerse definitivamente del imperio espiritual del papado. De allí, concluye que los documentos deben interpretarse desde una verdadera teoría del equilibrio. Para ello explica que la Reforma produjo la escisión de la cristiandad en el siglo XVI, lo que significó la ruptura del lazo religioso, que era el más sólido de los tantos lazos que unieron a los pueblos de la Edad Media. Y las consecuencias políticas de la escisión fueron graves: los Estados tomaron conciencia de su distinta personalidad y surgió un clima de desconfianza que se tradujo en una mutua vigilancia. Así, los tratados de 1648 siembran la semilla para equilibrar fuerzas con mecanismos que optimicen el resultado de la guerra a favor de los vencedores, pero que también tiendan a evitar una conflagración futura.

Se trata de un equilibrio entre naciones vecinas que están interrelacionadas por sus intereses con tanta intensidad, que los progresos particulares, aún menores, pueden alterar el sistema general, basado en seguridad colectiva y el reposo común. La mantención del statu quo hace que las ligas defensivas sean tan justas como necesarias, un mecanismo de precaución contra una nación que ostentase la capacidad de invadirlo todo. A su vez, esta idea de equilibrio varía según se analice desde una dimensión política o desde la dimensión jurídica. En la política, constituye un sistema asertivo, pues el equilibrio de fuerzas hace aleatorio el resultado de la guerra y esa incertidumbre es una de las mejores garantías para mantener la paz. Pero en la dimensión jurídica, la ausencia de una norma superior convierte al equilibrio en un fin, cuyo medio es la aplicación de la ley del más fuerte, obviamente en detrimento del Estado más débil (Domínguez Cámpora, 1947, p. 27-28). Paolillo (1993, p. 173-174) va a coincidir, considerando a la Paz de Westfalia un compromiso recíproco de cada potencia con las demás, redactado de tal forma que se dificulta la ruptura de la paz establecida. Si algún Estado parte quebrantaba la paz, se derrumbaba todo el edificio político continental.

En concreto, para Domínguez Cámpora (1947: 25-26) el equilibrio se asocia a la seguridad colectiva al establecerse que, en caso de agresión de un Estado germánico a otro, el agredido sería defendido no solo por los demás Estados germánicos, sino también por los países signatarios de los tratados. Todas las partes adquirían el rol de garantes que suponía la prohibición de unificar al Sacro Imperio Romano Germánico, un peligro para la paz continental. En esa línea Paolillo (1993, p. 173) argumenta que los tratados establecen una "paz alemana", ya que no hay nada en ellos que no refiera directa o indirectamente al Sacro Imperio. No obstante, agrega que por las consecuencias que tuvo, el documento establece una "paz europea". Hasta ese momento, una guerra terminaba por el triunfo de una de las partes, por el cansancio de ambas o por una solución satisfactoria, aunque fuera transitoria. Se trataba de treguas para la preparación de un nuevo conflicto. En cambio, el objetivo de Westfalia responde al equilibrio continental entre los máximos protagonistas, Francia, Suecia, España y el Sacro Imperio Romano Germánico con la 
finalidad de impedir que alguno acrecentara poder. Así, el que aparecía más fuerte, sobre todo en la mitad de la guerra, cuando las fuerzas suecas se estaban batiendo en retirada, era el Sacro Imperio, y Francia se esforzó en debilitarlo.

El Congreso de Viena de 1815, tiene una manifestación medular de equilibrio de poder que no difiere demasiado de lo acordado en Westfalia con: reasignaciones territoriales que suponen un reparto entre las cuatro principales potencias vencedoras; la consolidación de Estados tapones, y, nuevamente, un ordenamiento de Alemania que impide la instauración de un Estado nacional, aunque confirma su secularización. Francia, obviamente, pierde sus conquistas y regresa a las fronteras de 1792, pero rodeada de Estados tapones. España y Portugal ven restaurado el absolutismo, pero no recompensada su intervención en las luchas napoleónicas. No obstante, una muestra peculiar del equilibrio de poder en el Congreso, lo constituye el precepto que la derrotada Francia debía ser contemplada, pues su exclusión podría derivar en un equilibrio precario.

Por tanto, el Congreso tiene un objetivo mayúsculo que radica en explorar una fórmula que asegure un nuevo equilibrio político ante la derrota del proyecto expansionista francés. Como consecuencia para Veida (1993, p. 33), la situación europea posterior al Congreso evidenció un interés común de los vencedores en conservar el statu quo, ya que los Estados con capacidad de alterarlo, estaban satisfechos con lo obtenido en materia de reclamaciones territoriales e instauración de zonas de influencia. A su vez, los arreglos necesitaban de las herramientas aptas para perpetrar el sistema establecido. Estas herramientas para Kinder y Hilgemann (1990, p. 41) supusieron la instauración de un acuerdo de monarquías de naturaleza cristiana y patriarcal, bajo un régimen de defensa mutua y solidaria que incluía la potestad de intervención contra toda clase de aspiraciones nacionalistas y liberales.

Como se explicara, en ese esquema, la Santa Alianza fue inspiración del zar de Rusia Alejandro I (greco-ortodoxo) quien convoca a los monarcas de Austria (católico) y Prusia (protestante) bajo la protección divina de la Santísima Trinidad para la defensa de la religión, la paz y la justicia. En definitiva, este pacto internacional inspirado en Viena y formateado en la Santa Alianza debió ser complementado por las disposiciones prácticas de la Cuádruple Alianza. Las tres potencias originales se arrogan la responsabilidad de tutelar la convivencia pacífica en Europa. Y la adhesión de Gran Bretaña se explica, principalmente, por su afán de evitar un resurgimiento revolucionario y expansivo en Francia.

En el Congreso de Verona de 1822, ante la iniciativa de Francia, acompañada por las demás potencias europeas, pero con la oposición de Gran Bretaña, la coalición de monarquías decide intervenir en España, derrocando al gobierno liberal y restituyendo a Fernando VII. Esto despierta el temor británico que la restitución incluya el apoyo a España para recuperar sus colonias en América y ofrece a Estados Unidos de América, la firma de una declaración conjunta, rechazando posibles intervenciones europeas en el continente. El gobierno del país del norte, encabezado por James Monroe, también preocupado por los avances de Rusia en Alaska, si bien rechaza la declaración conjunta, concreta su posición en el mensaje anual al Congreso, el 2 de diciembre de 1823. En el mensaje, como se sabe, Monroe reivindica la jurisdicción soberana de los territorios en América, advirtiendo que no podrán considerarse campo de futura colonización por potencias europeas.

La comprensión cabal del equilibrio de poder que se genera y se intenta perpetuar a partir de la Conferencia de Paz de París por las potencias vencedoras, requiere asentir que la propia Primera Guerra Mundial cuestionó la herencia eurocentrista, arraigada principalmente por las dos anteriores cumbres ordenadoras del sistema internacional en Westfalia y Viena. En efecto, la nueva naturaleza geopolítica en el sistema "sepultaba definitivamente el sistema de equilibrio de poder emanado de la Paz de Westfalia, un sistema interestatal de matriz europea, para dejar paso a una realidad internacional que había dejado de ser eurocéntrica y euro determinada y en tránsito hacia una plena mundialización, cuyos síntomas comenzaban a evidenciarse desde la década de 1890" (Neila Hernández et al., 2018, p. 159). Esta aseveración encuentra cuatro fundamentos empíricos desde una mirada propia del equilibrio de poder. El primero radica en la alteración del ya restringido peso de la aristocracia en los Estados nacionales, sobre todo por el debilitamiento 
de los cuatro imperios dominantes: el alemán, el austro-húngaro, el ruso y el otomano. El segundo se comprueba con la presencia protagónica de dos potencias extra continentales desde las confrontaciones bélicas: Japón y Estados Unidos de América. El tercer fundamento conlleva el reconocimiento que, en este escenario inédito, la irrupción de Japón auguraba el quiebre a la influencia exclusivamente occidental en el mapa a proyectarse. El cuarto reside en el intento de darle protagonismo a un actor gubernamental pero no estatal, una Organización Internacional de alcance geográfico universal y fines generales que incluyeron la seguridad colectiva.

De hecho, a partir de la decisiva intervención en la guerra de Estados Unidos de América, Wilson intentó liderar la gestación de una nueva concepción de sistema internacional. Esa nueva concepción que marca los postulados del llamado Idealismo Clásico como teoría fundadora e inserta en la tradición liberal de las Relaciones Internacionales, se asienta como matriz renovadora en el marco de cumbres internacionales. Liberalismo, democracia y capitalismo completan una fórmula para un relacionamiento entre unidades nacionales, muy diferente a las ecuaciones ensayadas anteriormente por las potencias europeas.

¿Cuál fue la reacción en Europa de este mentado liderazgo extra continental? Gran Bretaña llega a la cumbre como la potencia europea con mayor afinidad con estos postulados. Paralelamente, muestra gran sensibilidad por un drástico debilitamiento de Alemania, motivada en su histórico temor al predomino de Francia en Europa. No obstante, los británicos atendían el peligro alemán con relación a su flota y a sus dominios coloniales. Francia llega muy debilitada por su participación en la guerra. Esto se pondrá en evidencia tanto en su concepción sobre una Organización Internacional con un rol novedoso en materia de seguridad como en sus firmes posturas sobre equilibrios geopolíticos y de recursos naturales en Europa. El interés nacional francés girará en torno a la seguridad en general y a una posible revancha de Alemania, más que en torno a sus dominios extra continentales. En concreto, los esfuerzos se concentraron en interponer una barrera con la creación de Estados independientes entre el Río Rhin y sus fronteras, administrados por la Liga de las Naciones. Italia negocia legitimando sus reivindicaciones en las promesas asumidas por Francia y Gran Bretaña, consciente de su condición de potencia débil. Su interés estratégico territorial lo ubicó en la margen oriental del Mar Mediterráneo y África. Estas prioridades hicieron que no se alineara plenamente con las ideas rectoras de Wilson. Japón se posicionó como otro aliado extra europeo triunfante, pero obviamente sin reivindicar intereses territoriales en Europa. No obstante, también enfrentaba a los intereses alemanes en su intención de mantener los derechos sobre Shantung, en su jurisdicción desde 1914, con vistas a una futura penetración sobre China.

En definitiva, el tratado se firmó sobre compromisos subyacentes muy básicos. El primero supone un balance entre la concepción británica del equilibrio de poder y la concepción idealista wilsoniana de la seguridad colectiva. El segundo compromiso subyacente conlleva un balance entre la intransigencia francesa y una mayor flexibilidad británica sobre el futuro de Alemania. No obstante, también se comprueba, como tercer compromiso subyacente, un balance entre el interés nacional de Francia por garantizar su seguridad y la aspiración universalista de la concepción de Wilson de fundar la Liga de las Naciones (Neila Hernández et al., 2018, p. 173).

Estos equilibrios precarios para Veida (1993, p. 267), “crearon en Europa un vacío de poder, que sería llenado por el Estado que estuviera en mejores condiciones para reindustrializarse y rearmarse". En primer lugar, porque el gobierno alemán queda como garante de su desarme y del pago de las reparaciones de guerra. En segundo lugar, en un contexto donde Rusia estaba muy debilitada, porque los pequeños Estados creados en los tratados no tenían el peso suficiente para equilibrar el poderío alemán y la posible contención volvía a recaer en las debilitadas Francia e Italia. En tercer lugar, porque los líderes de la cumbre perdieron el apoyo en el propio sistema político de sus países con las derrotas electorales inmediatas de Georges Clemenceau en Francia y Vittorio Emanuele Orlando en Italia, y, posteriormente, de Lloyd George en Gran Bretaña y de Wilson. En cuarto lugar, como explica Domínguez Cámpora (1947, p. 172) porque la creación de la Liga de las Naciones irrumpe en el sistema internacional como un instrumento de los vencedores de la guerra; la inclusión de su carta orgánica en el propio Tratado de Versalles - 
opción impuesta por Wilson para que de esa forma al Congreso de su país le fuera más fácil aceptar el ingreso a la Organización- no ayudó a que la institución trascendiera el contexto y el espíritu de la guerra que acababa de finalizar, con vencidos y vencedores.

Finalmente, la explicación más comprehensiva del principio de equilibrio de poder en la Conferencia de San Francisco, se halla en las reglas sobre membresía que estampa la Carta de las Naciones Unidas. Así, la propia condición de miembro de la Organización responde al equilibrio bipolar fundante y a un reconocimiento a las cinco potencias aliadas vencedoras en la Segunda Guerra Mundial. En este análisis de carácter institucional, cabe atender al mentado equilibrio de poder, desde otro de los compromisos políticos que Carrillo Salcedo (1987, p. 11) considera fundantes de las Naciones Unidas: el papel predominante y la responsabilidad primordial de las grandes potencias en el mantenimiento de la paz y seguridad internacionales a partir de arrogarse el veto en el Consejo de Seguridad.

El argumento de la incorporación de cinco miembros permanentes, paradojalmente, está contenido en el artículo 23 parágrafo 1, relativo a la designación de los miembros no permanentes. Así, el texto determina su elección a través de la Asamblea por dos años: "prestando especial atención, en primer término, a la contribución de los Miembros de las Naciones Unidas al mantenimiento de la paz y la seguridad internacionales y a los demás propósitos de la Organización, como también a una distribución geográfica equitativa”. La exigencia de ponderar esa contribución, razón central de la membresía permanente, en un principio se interpretó desde un criterio netamente material y bélico. No obstante, se ha aplicado desde criterios más amplios que comprenden una especie de adscripción moral, medida por líneas de política exterior de los Estados nacionales que demuestren una observancia permanente por los principios contenidos en la Carta.

En cuanto al veto concedido a los cinco miembros permanentes, puede considerarse como un resguardo, cuyo origen abreva al criterio de la unanimidad requerida en las conferencias internacionales sobre la base del principio de la igualdad de los Estados. Sin embargo, el veto en las Naciones Unidas puede darse sin unanimidad o, mejor dicho, desde una unanimidad restringida a ciertos Estados. ${ }^{12}$ Lo que debe tenerse en cuenta es que para que exista el derecho de veto, es necesario que se consagre una decisión orgánica emanada de la institución internacional respectiva. Así, la Carta de las Naciones Unidas le da al Consejo de Seguridad la potestad exclusiva de determinar si se ha configurado un acto de agresión en el artículo 39. Y una vez que lo determina, esa configuración adquiere carácter obligatorio para todos los miembros de la Organización. Esta facultad es una disposición inédita en la historia de las relaciones internacionales. Configura un régimen sobre mantenimiento de la paz y la seguridad internacionales desde la introducción de "un elemento genuinamente gubernamental, como es el poder de imponer determinada conducta a todos los Estados miembros" (Jiménez de Aréchaga, 1994, p. 85).

En definitiva, el veto es un auténtico resultado del equilibrio de poder. En la Conferencia de San Francisco, los medianos y pequeños Estados estuvieron dispuestos a aceptarlo. A su vez, las cinco grandes potencias no querían verse obligadas por una decisión del propio Consejo en la que no estuvieran de acuerdo. En este sistema, el derecho al veto es más que la mera prerrogativa de mantenerse al margen de cumplir y ejecutar una decisión en la que no se esté de acuerdo, es la potestad de imponer una posición política impidiendo la adopción de la decisión. Pero simultáneamente, el trasfondo de equilibrio de poder que se consagra, también revela la necesidad de las cinco grandes potencias de defenderse, unas de otras, mediante un mecanismo institucional. Se trata de impedir que una mayoría en el Consejo de Seguridad ejerza una acción coercitiva amparada en la propia legalidad de las Naciones Unidas. Si no fuera este el trasfondo, hubiera

\footnotetext{
${ }^{12}$ A su vez en los Organismos Internacionales, se puede dar la hipótesis de la unanimidad sin veto, cuando en la carta constitutiva se establece que los Estados pueden llegar a una resolución que obligue solamente a quienes la votaron, dejando exentos de toda obligación a los Estados disidentes.
} 
bastado con la fórmula de la unanimidad sin veto, aquella que permite a los Estados que votaron en contra, escindirse de la obligación que impuso la mayoría en el respectivo órgano.

\section{Conclusiones}

Con respecto a la evolución de la conflictividad del sistema en función del número de grandes potencias, el estudio aportó dos evidencias empíricas. La primera de ellas es que la estructura del sistema internacional en el período 1500-2000 en ningún momento registró una configuración unipolar, y lo que ha predominado ha sido una estructura de tipo multipolar alta. Una segunda evidencia fue que las guerras entre potencias previas a los arreglos institucionales de alcance mundial registraron mayores niveles de conflictividad. A saber: la Guerra de los Treinta Años, las Guerras Napoleónicas, la Primera Guerra Mundial y la Segunda Guerra Mundial. Indudablemente el desarrollo de estos conflictos incidió sensiblemente para que la conflictividad del sistema internacional, registrara sus mayores niveles de conflictividad en los períodos previos a las cumbres celebradas.

Igualdad jurídica, soberanía y equilibrio de poder parecen cerrar una ecuación que se constituirá en la explicación de la Paz de Westfalia. Los textos, desechan la idea de la Europa unitaria y monolítica como aspiraban el papa y el emperador. Se consagra un sistema laico de Estados independientes (soberanía), en el cual es indiferente el régimen político y la orientación religiosa de cada uno (igualdad), generando una nueva estructura internacional en base a Estados nacionales que flotarán en el sistema internacional sin un poder coactivo central (equilibrio). Asimismo, queda claro que se establece una paz de alcance continental con asignaciones territoriales que premiaron ganadores, pero previendo un equilibrio entre Estados poderosos y el fortalecimiento garantista de ciertos Estados de capacidades medias como freno a pretensiones expansionistas. El Congreso constituye un punto de inflexión en el sistema internacional relativo a la celebración de tratados multilaterales en contextos de congresos integrados por un importante número de Estados, todo bajo el respeto a las obligaciones contraídas -pacta sunt servanda- como principio basado en la viabilidad del instrumento y en la certeza de lo acordado, y no en una concepción religiosa.

El Congreso de Viena constituye una verdadera alteración de la igualdad jurídica con relación a lo acordado en Westfalia, desde una notoria desigualdad funcional patentizada por la propia negociación restringida a las potencias vencedoras. La garantía de perpetrar el statu quo de lo obtenido en el Congreso, es clave para entender los pactos entre monarquías que se arrogaron el derecho de rechazar formas de gobierno afines a ideas revolucionarias en terceros países. Asimismo, el atributo de la soberanía es gravemente desconocido: la Santa Alianza es fundamentada en valores cristianos como relato de cohesión interna y la Cuádruple Alianza afianza un pacto entre monarquías que acuerdan una garantía recíproca mediante el deber colectivo de asistencia mutua que, valida un régimen político, y se atribuyen la facultad de intervenir en terceros Estados, a quienes monitorean con reuniones periódicas. Finalmente, Viena representa un ícono de equilibrio de poder, pero desde una lectura que incluye a las cuatro potencias dominantes, al interés de ellas en no dejar a Francia muy aislada y a la consolidación del estatuto de Estados neutralizados y Estados tapones para dibujar un mapa que desaliente las aventuras expansionistas.

Las negociaciones en la Conferencia de Paz de París también excluyen actores internacionales, en una primera manifestación que demuestra la desigualdad real, consagra una desigualdad funcional y atenta contra la igualdad jurídica. No obstante, la personalidad internacional de Alemania, la gran derrotada en la guerra, tuvo que ser contemplada por vía de los hechos como garantía para cumplir con su desarme y las reparaciones económicas, ante la ausencia de mecanismos coercitivos para forzar el cumplimiento. Estados Unidos de América intentó liderar una nueva concepción del sistema internacional, monitoreado por la Liga de las Naciones y con la fórmula liberalismo-democracia-capitalismo, sustituyendo la vieja matriz concertista europea de base oligárquica, pero introduciendo principios propios de un sistema 
político interno como guía para las relaciones internacionales. En cuanto al principio de soberanía, se inauguran dos tensiones en el sistema internacional: las potestades de la Liga entran en colisión con los intereses soberanos de los Estados, incluso de los vencedores, y el diseño sistémico basado en los principios liberales y democráticos entra en colisión con el derecho a la autodeterminación de los pueblos. De aquí deriva la fórmula sui generis del mandato en favor de una Organización Internacional como tiempo de impase en materia de soberanía para las excolonias. Finalmente, el equilibrio de poder que intenta establecerse, por primera vez trasciende el espacio europeo y las perspectivas occidentales con el protagonismo de Estados Unidos de América y Japón. El intento norteamericano de un nuevo paradigma de equilibrio principista para dar sustento a una seguridad colectiva, es apoyado por Gran Bretaña, temerosa de que un drástico debilitamiento de Alemania reavivara la ambición expansionista de Francia. La Liga de las Naciones también surge como un instrumento de equilibrio de poder que, aunque plagada de debilidades, responde a los vencedores de la guerra. La composición de su Consejo se refleja en un directorio de potencias dominantes como garantes de lo acordado, pero en un futuro inmediato tradujo las posiciones privilegiadas que fueron ostentando otros Estados, inclusive Alemania.

Finalmente, la Carta de las Naciones Unidas, consagrada en la Conferencia de San Francisco, cristaliza la diferencia entre igualdad jurídica, desigualdad de hecho y diferencia funcional, traducida en: la distinción entre miembros permanentes y no permanentes de la Organización y de su Consejo de Seguridad; la facultades plenarias de la Asamblea General y la facultad excluyente del Consejo; el derecho de voto a todos los Estados miembros en la Asamblea y el poder de veto a los miembros permanentes en el Consejo; el valor de recomendación de las decisiones de la Asamblea y el valor obligatorio de todas las decisiones del Consejo basado en su capacidad coercitiva y sancionatoria. El principio de soberanía quedará enmarcado entre dos tensiones que delinearán el sistema internacional de posguerra. La primera se comprueba con las atribuciones supranacionales cedidas por los Estados miembros a un grupo de Estados que integrarán el Consejo, potenciadas con la consagración del veto en su seno. La segunda tensión desató la necesidad de un equilibrio entre las aspiraciones de independencia de los pueblos y territorios sometidos a colonialismo con los intereses de las grandes potencias coloniales. Finalmente, el principio del equilibrio de poder se demuestra en el liderazgo de cinco Estados vencedores de la guerra. Su derecho al veto refleja esta situación, aunque ya desde las negociaciones previas a San Francisco, Estados Unidos de América y Unión Soviética se reposicionaron como grandes potencias y relegaron a las otras tres a un segundo plano. De todas formas, se trata de un mecanismo de corte gubernamental en las manos privilegiadas de cinco Estados: la capacidad y potestad de una Organización Internacional de imponer determinada conducta a todos sus Estados miembros.

\section{Bibliografía}

Arbuet-Vignali, H. y Jiménez de Aréchaga, E. (2010). Los principios generales de Derecho Internacional que rigen las relaciones internacionales, en Arbuet-Vignali, H. y Puceiro Ripoll, R., Derecho Internacional Público. Breviario, Tomo I. Montevideo, Uruguay: Fundación de Cultura Universitaria

Bull, H. (2005). La sociedad anárquica. Un estudio sobre el orden en la política mundial, $2^{\mathrm{a}}$ Edición. Madrid, España: Catarata

Carrillo Salcedo, J. A. (1987). Las Naciones Unidas entre 1945 y 1986, en $O N U$ : año XL, en Revista de la Facultad de Derecho de la Universidad Complutense, vol. 13, pp. 11-32

Denton, F. y Warren, P. (1968). Some Patterns in the History of Violence, en Journal of Conflict Resolution, vol. 12, n 2, June, pp. 182-195

Diez de Velasco, M. (1990). Las Organizaciones Internacionales. Madrid, España: Tecnos 
Domínguez Cámpora, A. (1947). Derecho Internacional Público. Montevideo, Uruguay: Organización Taquigráfica Medina

Doran, C. (1991). Systems in crisis. New imperatives of high politics at century's end. New York, USA: Cambridge University Press

Fernández Luzuriaga, W. y Olmedo Hernández, H. (2015). Autonomía de los Estados nacionales y cláusulas democráticas de los Organismos Internacionales: una tensión en el sistema internacional contemporáneo, en Crítica Contemporánea, $\mathrm{N}^{\circ}$ 5, pp. 145-180, diciembre. Recuperado de: https://cienciassociales.edu.uy/institutodecienciapolitica/wpcontent/uploads/sites/4/2015/12/Fernandez_Luzuriaga_y_Olmedo_Gonzalez.pdf.

Consulta: 21 de febrero de 2020

Fernández Luzuriaga, W. y Olmedo Hernández, H. (2018). Conflictividad y órdenes mundiales: la Paz de Westfalia y la inauguración del sistema internacional contemporáneo, en Revista Crítica Contemporánea., $\quad \mathrm{N}^{\mathrm{o}} \quad 8$, pp. 48-75, diciembre. Recuperado de: https://www.colibri.udelar.edu.uy/jspui/bitstream/20.500.12008/21106/1/CC Fernandez -Olmedo 2018n8.pdf. Consulta: 21 de febrero de 2020

Fernández Luzuriaga, W. y Olmedo Hernández, H. (2019a). Conflictividad y órdenes mundiales: el Congreso de Viena y el intento de un freno a la historia de los principios de soberanía y de igualdad jurídica, en Revista Oasis, $\mathrm{N}^{\circ}$ 29, pp. 237-255, enero-junio. Recuperado de: https://dialnet.unirioja.es/servlet/articulo?codigo=7016536. Consulta: 21 de febrero de 2020

Fernández Luzuriaga, W. y Olmedo Hernández, H. (2019b). Conflictividad y órdenes mundiales: la Conferencia de San Francisco, un nuevo equilibrio sistémico y la consagración del multilateralismo universal, en Cuaderno das Relações Internacionais e Defesa, vol.1, $\mathrm{n}^{\circ} 1, \quad$ pp. 2-19, número inaugural. Recuperado de: https://periodicos.unipampa.edu.br/index.php/CRID/issue/view/41/11. Consulta: $21 \mathrm{de}$ febrero de 2020

Fernández Luzuriaga, W. y Olmedo Hernández, H. (2020). Conflictividad y órdenes mundiales la Conferencia de Versalles, el inicio de los equilibrios sistémicos y el primer intento de un multilateralismo universal, en Revista de Relaciones Internacionales, Estrategia y Seguridad, vol. 15, № 1, pp. 13-30, enero-junio.

Gilpin, R. (1981). War and Change in World Politics. New York, USA: Cambridge University Press

Gleditsch, N. y Hegre, H. (1997). Peace and Democracy: A More Skeptical View, en Journal of Conflict Resolution, vol. 41, n², pp. 283-310

Golstein, J. (1988). Long Cycles: Prosperity and War in the Modern Age. Connecticut, USA: Yale University Press

Jackson, P. (2011). The Conduct of Inquiry in International Relation. Philosophy of Science and Implications for the Study of World Politics. Ithaca, USA: Cornell University Press

Jervis, R. (1989). The meaning of the nuclear revolution. Statecraft and the Prospect of Armageddon. New York, USA: Cornell University Press

Jiménez de Aréchaga, E. (1980). El Derecho Internacional Contemporáneo. Madrid, España: Tecnos

Jiménez de Aréchaga, E. (1994). Las Naciones Unidas, en Arbuet-Vignali, H., Jiménez de Aréchaga, E. y Puceiro Ripoll, R., Derecho Internacional Público, Tomo V, $2^{\mathrm{a}}$ Edición. Montevideo, Uruguay: Fundación de Cultura Universitaria

Jiménez de Aréchaga, E. (1995). Reconocimiento de Estado, gobierno y beligerancia, en ArbuetVignali, H., Jiménez de Aréchaga, E. y Puceiro Ripoll, R., Derecho Internacional Público, Tomo II. Montevideo, Uruguay: Fundación de Cultura Universitaria 
Kennedy, P. (2006). Auge y caída de las grandes potencias. Buenos Aires, Argentina: Ediciones Debolsillo

Kinder, H. y Hilgemann, W. (1990). Atlas Histórico Mundial II. De la Revolución Francesa a nuestros días, $15^{\text {a }}$ Edición. Madrid, España: Ediciones ISTMO

Kissinger, H. (1973). Un mundo restaurado. México DF, México: Fondo de Cultura Económica

Lemke, D. (2002). Regions of Wars and Peace. New York, USA: Cambridge University Press

Levy, J. (1983). War in the Modern Great Power System 1495-1975. Kentucky, USA: The University Press of Kentucky

McLaughlin, S. (1999). Evolution in Democracy-War Dynamic, en Journal of Conflict Resolution, vol. 43, n6, pp. 771-792

McLaughlin, S. (2012). Norms and the Democratic Peace, en J. Vásquez (ed.). What do we know about war? Maryland, USA: Rowman \& Littlefield Publishers

Mearsheimer, J. (2001). The Tragedy of Great Power Politics. New York, USA: W.W. Norton \& Company Inc.

Modelski, G. (1987). Long Cycles in World Politics. London, UK: The Macmillan Press

Morgenthau, H. (1986). Política entre Naciones. La lucha por el poder y la paz, $3^{\text {a }}$ Edición. Buenos Aires, Argentina: Grupo Editor Latinoamericano

Neila Hernández, J. L.; Moreno Juste, A.; Alija Garabito, A. M.; Sáenz Rotko, J. M. y Sanz Díaz, C. (2018). Historia de las relaciones internacionales. Madrid, España: Alianza Editorial

Organzky, A.F.K. y Kugler, J. (1980). The War Ledger. Chicago, USA: University of Chicago Press

Paolillo, F.H. (1993). El Congreso de Viena, en Arbuet-Vignali, H. (dir.). Lecciones de Historia de las Relaciones Internacionales, Tomo II. Montevideo, Uruguay: Fundación de Cultura Universitaria

Paolillo, F.H. (1993). Los tratados de Westfalia, en Arbuet-Vignali, H. (dir.). Lecciones de Historia de las Relaciones Internacionales, Tomo II. Montevideo, Uruguay: Fundación de Cultura Universitaria

Renouvin, P. (1990). Historia de las Relaciones Internacionales. Siglos XIX y XX, Segunda edición. Madrid, España: AKAL

Richardson, L.F. (1960). Statistics of Deadly Quarrels. Chicago, USA: Quadrangle

Sarkees, M. y Wayman, F. (2010). Resort to War 1816-2007. Washington DC, USA: CQ PressSAGE Publications

Tammen, R. (2000). Power Transitions. Strategies for the 21st Century. New York, USA: CQ Press-SAGE Publications

Veida, V. (1993). La Santa Alianza, en Arbuet-Vignali, H. (dir.). Lecciones de Historia de las Relaciones Internacionales, Tomo II. Montevideo, Uruguay: Fundación de Cultura Universitaria

Veida, V. (1993). Regulación convencional de la Paz de 1919, en Arbuet-Vignali, H. (dir.). Lecciones de Historia de las Relaciones Internacionales, Tomo II. Montevideo, Uruguay: Fundación de Cultura Universitaria

Waltz, K. (1988). Teoría de la Política Internacional. Buenos Aires, Argentina: Grupo Editor Latinoamericano

Waltz, K. (2003). More may be better, in K. Waltz \& S. Sagan. The spread of the nuclear weapons. A debate renewed. New York, USA: Norton \& Company 
Wight, M. (1977). System of States, Leicester: Leicester University Press

Woods, F. \& Baltzy, A. (1915). Is War Diminishing? Boston, USA: Hougthon-Mifflin

Wright, Q. (1965). A Study of War, $2^{\mathrm{a}}$ Edition. Chicago, USA: University of Chicago

\section{Documentos}

Carta de la Organización de las Naciones Unidas (1945)

Convención de Viena sobre Derecho de los Tratados (1969)

Pacto de la Sociedad de las Naciones (1919)

\section{Materiales anexos}

\begin{tabular}{|c|c|c|c|c|c|c|c|c|c|c|}
\hline \multicolumn{11}{|c|}{ Polemograma del Sis tema Internacional $1500-2000$} \\
\hline Tiempo & N. G.Potencias & Frec. Guerras & Guerras Activas & N G. Potencias en Guerras. & Alc ance Prom & Duración & Duración Prom & nSeveridad $\$$ & Severidad Prom & I. Conflic tividad \\
\hline $1500-1525$ & 5 & 6 & 8 & 15 & 2,5 & 22 & 3,6 & 94200 & 11775 & $-0,46$ \\
\hline $1525-1550$ & 4 & 7 & 9 & 15 & 2,1 & 40 & 5,7 & 236000 & 26222 & $-0,37$ \\
\hline $1550-1575$ & 5 & 9 & 9 & 19 & 2,1 & 35 & 3,9 & 259800 & 28867 & $-0,47$ \\
\hline $1575-1600$ & 5 & 4 & 5 & 6 & 1,5 & 43 & 10,8 & 184400 & 36880 & $-0,13$ \\
\hline $1600-1625$ & 6 & 3 & 5 & 14 & 4,7 & 22 & 7,3 & 366540 & 73308 & $-0,03$ \\
\hline $1625-1650$ & 7 & 1 & 2 & 17 & 17,0 & 25 & 25,0 & 1875000 & 937500 & 2,28 \\
\hline $1650-1675$ & 7 & 7 & 8 & 23 & 3,3 & 34 & 49 & 369000 & 46125 & $-0,31$ \\
\hline $1675-1700$ & 7 & 3 & 4 & 15 & 5,0 & 30 & 10,0 & 1240000 & 310000 & 0,20 \\
\hline $1700-1725$ & 6 & 3 & 3 & 11 & 3,7 & 35 & 11,7 & 1340000 & 446667 & 0,20 \\
\hline $1725-1750$ & 5 & 3 & 3 & 12 & 4,0 & 17 & 5,7 & 462000 & 154000 & $-0,17$ \\
\hline $1750-1775$ & 6 & 1 & 1 & 6 & 6,0 & 8 & 8,0 & 992000 & 992000 & 0,32 \\
\hline $1775-1800$ & 6 & 2 & 3 & 11 & 5,5 & 15 & 7,5 & 697300 & 232433 & 0,09 \\
\hline $1800-1825$ & 5 & 1 & 2 & 6 & 6,0 & 12 & 12,0 & 1869000 & 934500 & 0,53 \\
\hline $1825-1850$ & 5 & 0 & 0 & 0 & 0,0 & 0 & 0,0 & 0 & 0 & $-0,90$ \\
\hline $1850-1875$ & 6 & 4 & 4 & 10 & 2,5 & 3 & 0,8 & 451000 & 112750 & $-0,60$ \\
\hline $1875-1900$ & 6 & 0 & 0 & 0 & 0,0 & 0 & 0,0 & 0 & 0 & $-0,90$ \\
\hline $1900-1925$ & 8 & 2 & 2 & 13 & 6,5 & 7 & 3,7 & 7739300 & 3869650 & 0,71 \\
\hline $1925-1950$ & 7 & 2 & 2 & 9 & 4,5 & 6 & 32 & 12964300 & 6482150 & 1,05 \\
\hline $1950-1975$ & 2 & 1 & 1 & 4 & 4,0 & 3 & 3,1 & 954960 & 954960 & $-0,15$ \\
\hline $1975-2000$ & 3 & 0 & 0 & 0 & 0,0 & 0 & 0,0 & 0 & 0 & $-0,90$ \\
\hline ell & ación prop. & & & & & & & & & \\
\hline
\end{tabular}


Cuadernos de Política Exterior Argentina (Nueva Época), 132, diciembre 2020, pp. 7-30

ISSN 0326-7806 (edición impresa) - ISSN 1852-7213 (edición en línea)

\begin{tabular}{|c|c|c|c|c|c|c|c|c|c|c|c|c|}
\hline \multicolumn{13}{|c|}{ Datos cuantitativos sobre Guerras entre grandes potencias - índice de Conflictividad } \\
\hline \multirow[b]{2}{*}{$\mathbf{N}^{\circ}$} & \multirow[b]{2}{*}{$N^{\circ}$ G. J. Levy } & \multirow[b]{2}{*}{ Nombre de guerras } & \multirow[b]{2}{*}{ Año inicio } & \multicolumn{3}{|c|}{ Frecuencias Absolutas } & \multicolumn{3}{|c|}{ Estandarización z } & \multirow[b]{2}{*}{ Conflictividad } & \multirow{2}{*}{\multicolumn{2}{|c|}{ Ordenadas por nivel de conflictividad }} \\
\hline & & & & Duración & Alcance & Severidad & Z Dur & Z Alc & $2 \mathrm{Sev}$ & & & \\
\hline 1 & 5 & G. Napolitana & 1501 & 3 & 2 & 18000 & $-0,50$ & $-0,65$ & $|-0,27|$ & $-0,47$ & G. 2a Guerra Mundial & 2,96 \\
\hline 2 & 7 & G. Liga Santa & 1511 & 3 & 4 & 18000 & $-0,50$ & 0,59 & $\mid-0,27$ & $-0,06$ & G. 30 Años & 2,51 \\
\hline 3 & 8 & G. Austro-Turca & 1512 & 7 & 2 & 24000 & 0,21 & $-0,65$ & $|-0,26|$ & $-0,24$ & G. 1a Guerra Mundial & 2,17 \\
\hline 4 & 10 & G. 2a Milanés & 1515 & 0,5 & 3 & 3000 & $-0,95$ & $-0,03$ & $-0,27$ & $-0,42$ & G. Napoleónicas & 1,20 \\
\hline 5 & 11 & G. 1a Carlos V & 1521 & 5 & 3 & 30000 & $-0,15$ & $-0,03$ & $-0,26$ & $-0,15$ & G. Sucesión española & 0,89 \\
\hline 6 & 12 & G. Otomana & 1521 & 10 & 2 & 68000 & 0,74 & $-0,65$ & $-0,24 \mid$ & $-0,05$ & G. Revolución francesa & 0,88 \\
\hline 7 & 14 & G. $2^{\text {a }}$ Carlos V & 1526 & 3 & 3 & 18000 & $-0,50$ & $-0,03$ & $|-0,27|$ & $-0,27$ & G. 7 Años & 0,82 \\
\hline 8 & 15 & G. Otomana & 1532 & 3 & 2 & 28000 & $-0,50$ & $-0,65$ & \begin{tabular}{|c|}
$-0,26$ \\
\end{tabular} & $-0,47$ & G. Sucesión Austríaca & 0,77 \\
\hline 9 & 17 & G. 3a Carlos V & 1536 & 2 & 2 & 32000 & $-0,68$ & $-0,65$ & $-0,26 \mid$ & $-0,53$ & G. Liga Augsburgo & 0,62 \\
\hline 10 & 18 & G. Otomana & 1537 & 10 & 2 & 97000 & 0,74 & $-0,65$ & $-0,23 \mid$ & $-0,05$ & G. $2^{\text {a }}$ G. Norteña & 0,60 \\
\hline 11 & 20 & G. 4a Carlos V & 1542 & 2 & 2 & 47000 & $-0,68$ & $-0,65$ & $-0,25$ & $-0,53$ & G. Holandés de Luis XIV & 0,59 \\
\hline 12 & 21 & G. Boulogne & 1544 & 2 & 2 & 8000 & $-0,68$ & $-0,65$ & $|-0,27|$ & $-0,53$ & G. De la Armada & 0,48 \\
\hline 13 & 22 & G. Arundel & 1549 & 1 & 2 & 6000 & $-0,86$ & $-0,65$ & $-0,27 \mid$ & $-0,59$ & G. Otomana & 0,42 \\
\hline 14 & 23 & G. Otomana & 1551 & 5 & 2 & 44000 & $-0,15$ & $-0,65$ & $-0,25 \mid$ & $-0,35$ & G. Revolución Rusa & 0,15 \\
\hline 15 & 24 & G. 5a Carlos V & 1552 & 4 & 2 & 51000 & $-0,32$ & $-0,65$ & $-0,25$ & $-0,41$ & G. Autro-turca & 0,13 \\
\hline 16 & 25 & G. Austro-Turca & 1556 & 6 & 2 & 52000 & 0,03 & $-0,65$ & \begin{tabular}{|l|}
$-0,25$ \\
\end{tabular} & $-0,29$ & G. Corea & 0,11 \\
\hline 17 & 26 & G. Franco-Española & 1556 & 3 & 3 & 24000 & $-0,50$ & $-0,03$ & $|-0,26|$ & $-0,27$ & G. Sucesión Polaca & 0,07 \\
\hline 18 & 27 & G. Escocesa & 1559 & 1 & 2 & 6000 & $-0,86$ & $-0,65$ & $-0,27 \mid$ & $-0,59$ & G. Franco-Española & 0,02 \\
\hline 19 & 28 & G. Turca-Española & 1559 & 5 & 2 & 24000 & $-0,15$ & $-0,65$ & $-0,26 \mid$ & $-0,35$ & G. Española-Turca & 0,00 \\
\hline 20 & 29 & G. 1a Huguenot & 1562 & 2 & 2 & 6000 & $-0,68$ & $-0,65$ & $|-0,27|$ & $-0,53$ & G. Otomana & $-0,01$ \\
\hline 21 & 30 & G. Austro-Turca & 1565 & 3 & 2 & 24000 & $-0,50$ & $-0,65$ & \begin{tabular}{|c|}
$-0,26$ \\
\end{tabular} & $-0,47$ & G. Otomana & $-0,05$ \\
\hline 22 & 31 & G. Española-Turca & 1569 & 11 & 2 & 48000 & 0,92 & $-0,65$ & \begin{tabular}{|c|}
$-0,25$ \\
\end{tabular} & 0,00 & G. Otomana & $-0,05$ \\
\hline 23 & 32 & G. Austro-Turca & 1576 & 7 & 2 & 48000 & 0,21 & $-0,65$ & $-0,25 \mid$ & $-0,23$ & G. Liga Santa & $-0,06$ \\
\hline 24 & 35 & G. De la Armada & 1585 & 19 & 2 & 48000 & 2,34 & $-0,65$ & $-0,25 \mid$ & 0,48 & G. Revolución americana & $-0,09$ \\
\hline 25 & 37 & G. Tres Reyes & 1589 & 9 & 2 & 16000 & 0,56 & $-0,65$ & $|-0,27|$ & $-0,12$ & G. Gran Noreste & $-0,09$ \\
\hline 26 & 38 & G. Autro-turca & 1593 & 13 & 2 & 90000 & 1,27 & $-0,65$ & $-0,23$ & 0,13 & G. Cuádruple Alianza & $-0,12$ \\
\hline 27 & 40 & G. Española-Turca & 1610 & 4 & 2 & 15000 & $-0,32$ & $-0,65$ & $|-0,27|$ & $-0,41$ & G. Tres Reyes & $-0,12$ \\
\hline 28 & 44 & G. Española-turca & 1618 & 1 & 2 & 6000 & $-0,86$ & $-0,65$ & $-0,27 \mid$ & $-0,59$ & G. 1를 Carlos V & $-0,15$ \\
\hline 29 & 45 & G. 30 Años & 1618 & 30 & 7 & 2071000 & 4,29 & 2,45 & 0,79 & 2,51 & G. Austro-Turca & $-0,23$ \\
\hline 30 & 52 & G. Franco-Española & 1648 & 11 & 2 & 108000 & 0,92 & $-0,65$ & \begin{tabular}{|c|}
$-0,22$ \\
\end{tabular} & 0,02 & G. Austro-Turca & $-0,24$ \\
\hline 31 & 54 & G.Naval Anglo-Holandés & 1652 & 3 & 2 & 26000 & $-0,50$ & $-0,65$ & $-0,26$ & $-0,47$ & G. Franco-Española & $-0,27$ \\
\hline 32 & 55 & G. Gran Noreste & 1654 & 6 & 3 & 22000 & 0,03 & $-0,03$ & $|-0,26|$ & $-0,09$ & G. 2a Carlos V & $-0,27$ \\
\hline 33 & 56 & G. Inglesa-española & 1656 & 3 & 2 & 15000 & $-0,50 \mid$ & $-0,65$ & $-0,27 \mid$ & $-0,47$ & G. Crimea & $-0,27$ \\
\hline 34 & 58 & G. Otomana & 1657 & 7 & 3 & 109000 & 0,21 & $-0,03$ & \begin{tabular}{|c|}
$-0,22$ \\
\end{tabular} & $-0,01$ & G. Austro-Turca & $-0,29$ \\
\hline 35 & 60 & G. Naval Anglo-Holandés & 1665 & 2 & 3 & 37000 & $-0,68$ & $-0,03$ & \begin{tabular}{|c|}
$-0,26$ \\
\end{tabular} & $-0,32$ & G. Naval Anglo-Holandés & $-0,32$ \\
\hline 36 & 61 & G. Devolutiva & 1667 & 1 & 2 & 4000 & $-0,86$ & $-0,65$ & \begin{tabular}{|l|}
$-0,27$ \\
\end{tabular} & $-0,59$ & G. Otomana & $-0,35$ \\
\hline 37 & 62 & G. Holandés de Luis XIV & 1672 & 6 & 6 & 342000 & 0,03 & 1,83 & $-0,10 \mid$ & 0,59 & G. Turca-Española & $-0,35$ \\
\hline 38 & 65 & G. Otomana & 1682 & 17 & 2 & 384000 & 1,98 & $-0,65$ & $-0,08$ & 0,42 & G. 5a Carlos V & $-0,41$ \\
\hline 39 & 66 & G. Franco-Española & 1683 & 1 & 2 & 5000 & $-0,86$ & $-0,65$ & $|-0,27|$ & $-0,59$ & G. Española-Turca & $-0,41$ \\
\hline 40 & 67 & G. Liga Augsburgo & 1688 & 9 & 5 & 680000 & 0,56 & 1,21 & 0,07 & 0,62 & G. 2a Milanés & $-0,42$ \\
\hline 41 & 68 & G. 2a G. Norteña & 1700 & 21 & 2 & 64000 & 2,69 & $-0,65$ & $-0,24 \mid$ & 0,60 & G. Asutria-Prusiana & $-0,44$ \\
\hline 42 & 69 & G. Sucesión española & 1701 & 12 & 5 & 1251000 & 1,10 & 1,21 & \begin{tabular}{|l|}
0,37 \\
\end{tabular} & 0,89 & G. Otomana & $-0,47$ \\
\hline 43 & 71 & G. Cuádruple Alianza & 1718 & 2 & 4 & 25000 & \begin{tabular}{|l|}
$-0,68$ \\
\end{tabular} & 0,59 & \begin{tabular}{|l|}
$-0,26$ \\
\end{tabular} & $-0,12$ & G.Naval Anglo-Holandés & $-0,47$ \\
\hline 44 & 72 & G. Brtánica-Española & 1726 & 3 & 2 & 15000 & $-0,50 \mid$ & $-0,65$ & $|-0,27|$ & $-0,47$ & G. Austro-Turca & $-0,47$ \\
\hline 45 & 73 & G. Sucesión Polaca & 1733 & 5 & 4 & 88000 & $-0,15$ & 0,59 & $-0,23 \mid$ & 0,07 & G. Napolitana & $-0,47$ \\
\hline 46 & 75 & G. Sucesión Austríaca & 1739 & 9 & 6 & 359000 & 0,56 & 1,83 & $-0,09$ & 0,77 & G. Inglesa-española & $-0,47$ \\
\hline 47 & 77 & G. 7 Años & 1755 & 8 & 6 & 992000 & 0,39 & 1,83 & 0,23 & 0,82 & G. Brtánica-Española & $-0,47$ \\
\hline 48 & 80 & G. Sucesión Bavaria & 1778 & 1 & 2 & 300 & $-0,86$ & $-0,65$ & \begin{tabular}{|l|}
$-0,28$ \\
\end{tabular} & $-0,59$ & G. 4a Carlos V & $-0,53$ \\
\hline 49 & 81 & G. Revolución americana & 1778 & 6 & 3 & 34000 & 0,03 & $-0,03$ & $|-0,26|$ & $-0,09$ & G. 3a Carlos V & $-0,53$ \\
\hline 50 & 84 & G. Revolución francesa & 1792 & 10 & 6 & 663000 & 0,74 & 1,83 & 0,07 & 0,88 & G. Boulogne & $-0,53$ \\
\hline 51 & 85 & G. Napoleónicas & 1803 & 12 & 6 & 1869000 & 1,10 & 1,83 & 0,69 & 1,20 & G. 1를 Huguenot & $-0,53$ \\
\hline 52 & 96 & G. Crimea & 1853 & 2,4 & 3 & 217000 & $-0,61 \mid$ & $\mid-0,03$ & \begin{tabular}{|l|} 
\\
\end{tabular} & $-0,27$ & G. Franco-Prusiana & $-0,59$ \\
\hline 53 & 98 & G. Unificación Italiana & 1859 & 0,2 & 2 & 20000 & $-1,00$ & $-0,65$ & \begin{tabular}{|l|} 
\\
\end{tabular} & $-0,64$ & G. Arundel & $-0,59$ \\
\hline 54 & 101 & G. Asutria-Prusiana & 1866 & 0,1 & 3 & 34000 & $-1,02$ & $-0,03$ & $-0,26 \mid$ & $-0,44$ & G. Escocesa & $-0,59$ \\
\hline 55 & 102 & G. Franco-Prusiana & 1870 & 0,6 & 2 & 180000 & $-0,93$ & $-0,65$ & $\mid-0,18$ & $-0,59$ & G. Española-turca & $-0,59$ \\
\hline 56 & 107 & G. 1a Guerra Mundial & 1914 & 4,3 & 8 & 7734300 & \begin{tabular}{|l|}
$-0,27$ \\
\end{tabular} & 3,08 & 3,70 & 2,17 & G. Franco-Española & $-0,59$ \\
\hline 57 & 108 & G. Revolución Rusa & 1918 & 3 & 5 & 5000 & $-0,50$ & 1,21 & \begin{tabular}{|l|}
$-0,27$ \\
\end{tabular} & 0,15 & G. Devolutiva & $-0,59$ \\
\hline 58 & 112 & G. Ruso-Japonesa & 1939 & 0,4 & 2 & 16000 & $-0,96$ & $-0,65$ & \begin{tabular}{|l|} 
\\
\end{tabular} & $-0,63$ & G. Sucesión Bavaria & $-0,59$ \\
\hline 59 & 113 & G. 2ª Guerra Mundial & 1939 & 6 & 7 & 12948300 & 0,03 & 2,45 & 6,39 & 2,96 & G. Ruso-Japonesa & $-0,63$ \\
\hline 60 & 115 & G. Corea & 1950 & 3,1 & 4 & 954960 & $|-0,48|$ & 0,59 & 0,22 & 0,11 & G. Unificación Italiana & $-0,64$ \\
\hline
\end{tabular}

